\title{
Effect of column base strength on steel portal frames in fire
}

1 Mahbubur Rahman BSC

Research Student in Structural Engineering, University of Strathclyde, Glasgow, Scotland, UK

2 James B. P. Lim BEng, PhD, CEng, MICE Lecturer in Structural Engineering, Queen's University, Belfast, Northern Ireland, UK

$3 \quad$ Yixiang $\mathrm{Xu}$ BEng, PhD

Lecturer in Structural Engineering, University of Strathclyde, Glasgow, Scotland, UK
4 Robert Hamilton BSc, PhD, CEng, MIMechE, FHEA Lecturer in Mechanical Engineering, University of Strathclyde, Glasgow, Scotland, UK

5 Tugrul Comlekci MSc, PhD, FHEA, CEng, MIMechE Lecturer in Mechanical Engineering, University of Strathclyde, Glasgow, Scotland, UK

6 David Pritchard MA, PhD Lecturer in Mathematics, University of Strathclyde, Glasgow, Scotland, UK
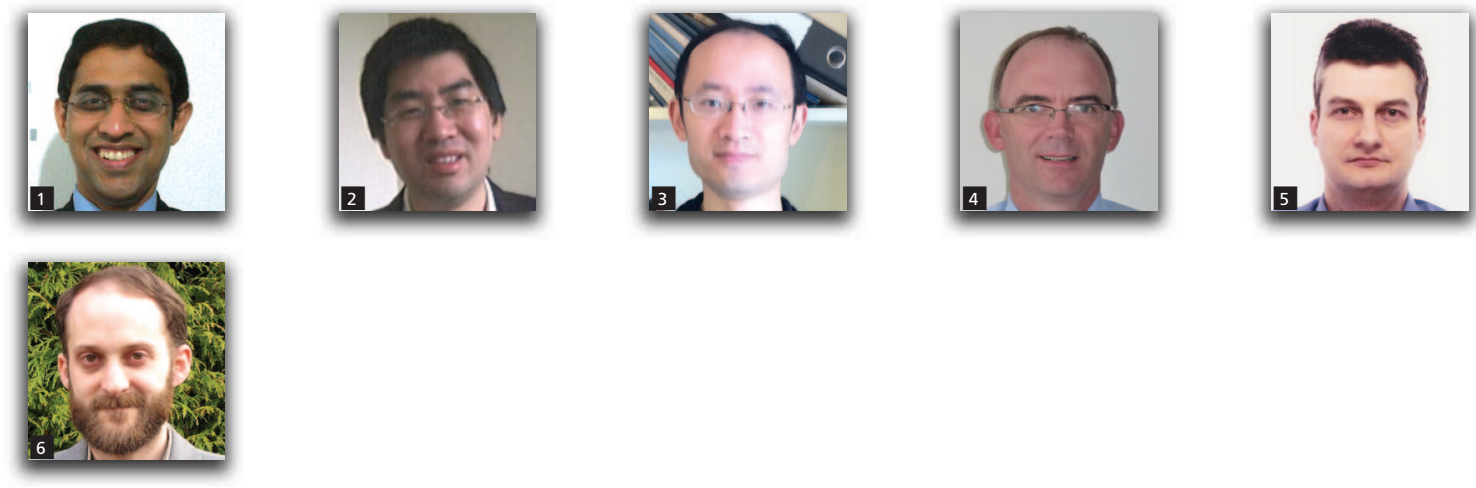

In the UK, the design of steel portal frame buildings in fire is based on the Steel Construction Institute (SCl) design method, in which fire protection needs only be provided to the columns, provided that the column bases are designed to resist an overturning moment, Мотм, calculated in accordance with the Steel Construction Institute design method. In this paper, a non-linear elastic-plastic implicit dynamic finite-element model of a steel portal frame building in fire is described and used to assess the adequacy of the Steel Construction Institute design method. Both two-dimensional and three-dimensional models are used to analyse a building similar to the exemplar frame described in the Steel Construction Institute design guide. Using the two-dimensional model, a parametric study comprising 27 frames is conducted. It is shown that the value of the overturning moment, calculated in accordance with the Steel Construction Institute design method, may not be sufficient to prevent collapse of the frame before $890^{\circ} \mathrm{C}$.

\section{Notation}

A area of the section

E Young's modulus

$h$ height of the column

$I_{\text {maj }}$ second moment of area about the major axis

$K_{\mathrm{b}} \quad$ non-dimensional rotational stiffness

$k_{\mathrm{b}} \quad$ initial column base rotational stiffness

$L \quad$ span of portal frame

$M_{\mathrm{p}} \quad$ plastic moment capacity of section

$M_{\mathrm{pf}} \quad$ fire hinge moment $\left(6 \cdot 5 \% M_{\mathrm{p}}\right)$

$M_{\mathrm{p}, \mathrm{col}}$ plastic moment capacity of column section

$M_{\mathrm{p}, \text { raf }}$ plastic moment capacity of rafter section

$M_{\text {OTM }}$ overturning moment

$M_{\mathrm{SCI}} \mathrm{M}_{\mathrm{OTM}}$ according to the SCI design guide (Simms and Newman, 2002)

$r$ ratio of applied load to ultimate load capacity of the frame
$W_{\mathrm{pl}} \quad$ plastic section modulus

$\theta \quad$ pitch of portal frame

\section{Introduction}

In the UK, single-storey steel portal frame buildings (Figure 1) account for over $50 \%$ of the constructional steelwork used each year. In fire, however, steel rapidly loses its strength and stiffness, and so for steel portal frame buildings designed in fire boundary conditions, expensive fire protection is often required in order to ensure structural integrity and prevent premature collapse.

The UK Building Regulations (DEW, 1991) make reference to the SCI design method (Simms and Newman, 2002), which suggests that expensive fire protection is only required for columns but not necessary for rafters, so long as the column bases are designed to resist an overturning moment $M_{\text {OTM }}$ 


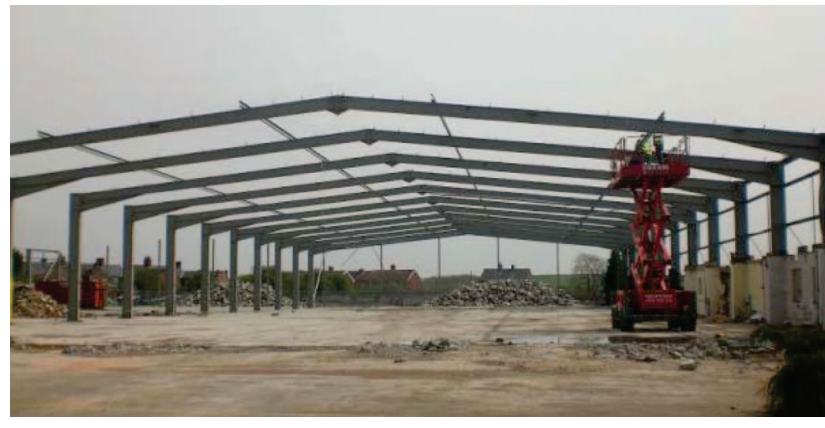

Figure 1. A typical portal frame building (without cladding, purlin and roofing)

calculated in accordance with the SCI design method. The SCI design method makes the assumption that the columns remain at ambient temperature (since fire protection is applied) and that both rafters are heated uniformly to a maximum temperature of $890^{\circ} \mathrm{C}$, which is the temperature at which $6.5 \%$ of the ambient strength of steel is assumed to remain. For a single-span building, it assumes that the rafters undergo symmetrical inward snapthrough buckling, after which the frame stabilises with the rafters being suspended below the columns in catenary action (see Figure 2). The SCI design method also assumes that the inverted position of the rafter after snap-through buckling is the ultimate limit state of the frame. In the UK, if a frame is designed in accordance with the SCI design method and the column bases are designed to be able to resist $M_{\mathrm{OTM}}$, the designer may assume that the columns will also remain $1^{\circ}$ from the vertical, thus preventing inward collapse of the walls.

According to the Australian design code, O'Meagher et al. (1992) defined acceptable and unacceptable modes of failure

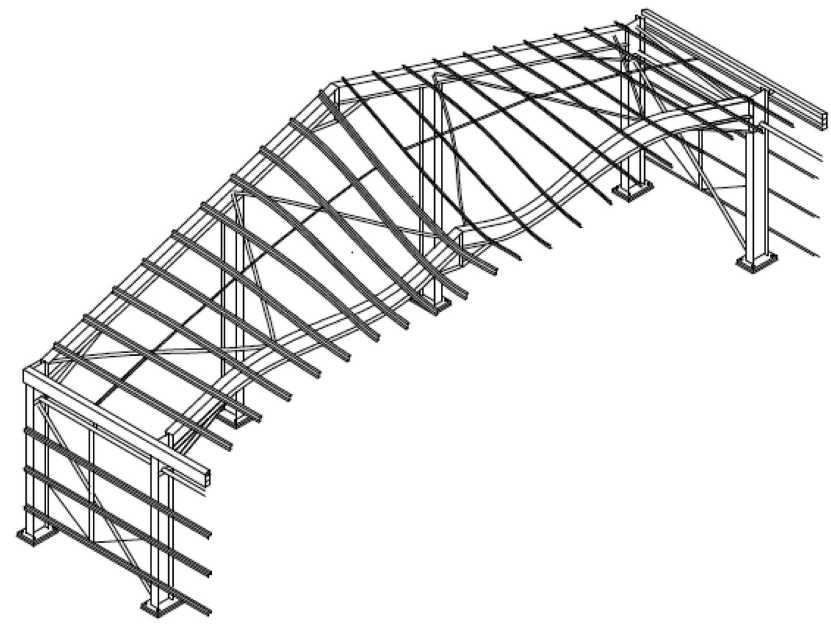

Figure 2. Symmetrical inwards snap-through-buckling collapse mechanism as assumed in $\mathrm{SCl}$ design guide (Simms and Newman, 2002)

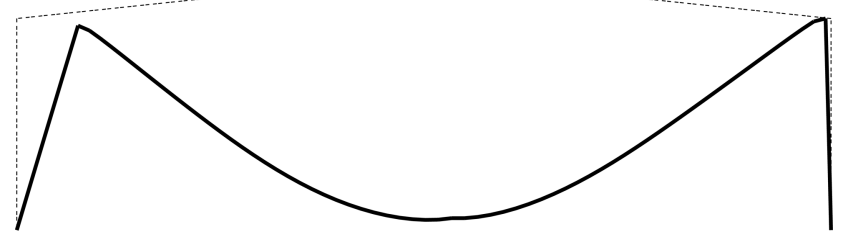

(a)

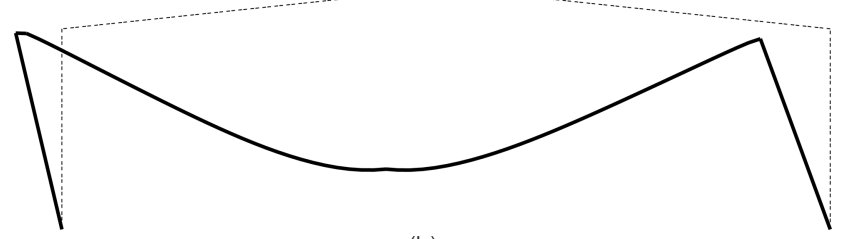

(b)

Figure 3. Asymetrical acceptable and unacceptable collapse mechanisms after O'Meagher et al. (1992)

(Figure 3). These modes of failure covered a number of different heating situations, for example, when only one column and one rafter are exposed to fire. As can be seen, the acceptable mode of failure is asymmetric (Figure 3(a)) with one column remaining near to vertical and the other column collapsing inwards. The unacceptable mode of failure is also asymmetric and results in outward wall collapse (Figure 3(b)), which is dangerous since it not only allows the fire to spread to adjacent buildings but also represents a danger to fire fighters and occupants escaping from the building owing to the collapsing walls.

Research over the past two decades has demonstrated that the mode of collapse of a single-span steel portal frame with both rafters heated uniformly is not always symmetric, as assumed by the SCI design method, but can be asymmetric and take either of the two failure modes defined by O'Meagher et al. (1992).

In 2001, Wong (2001) conducted full-scale fire tests on a hotrolled steel single-span portal frame with pinned column bases, and observed such asymmetrical behaviour. Using the finiteelement program Vulcan (Huang et al., 2004), Wong then conducted a two-dimensional (2D) non-linear, elastic-plastic, implicit static finite-element analysis and was able to predict the behaviour successfully up to the snap-through buckling temperature. Wong provided a design method for calculating the snapthrough buckling temperature, assuming pinned column bases.

Franssen and Gens (2004) described a double-span portal frame, which Vassart et al. (2007) adopted for their studies. Using the finite-element program Safir (Franssen et al., 2002), Vassart conducted a 2D non-linear, elastic-plastic, implicit dynamic finite-element analysis to predict the behaviour of the double-span frame to collapse. Ali et al. (2004) also conducted a 2D nonlinear, elastic-plastic, finite-element analysis of a double-bay frame using the finite-element program Abaqus (Simulia, 2009) in order to determine the safe clearance required between the 
frame and firewall allowing the frame to expand laterally. They observed that lateral displacement of frames increases with an increase of spatial extent of fire. They also observed that the greater the roof height, the sooner the failure of the frame occurs.

Song (2009) and Song et al. $(2008,2009)$ continued the work of Wong on single-span frames and used Vulcan to conduct a 2D non-linear, elastic-plastic, implicit dynamic analysis of the portal frame. Song et al. were able to predict the post-buckling behaviour and observed an asymmetric failure mechanism. For models in which the column bases were modelled assuming linear rotational stiffness, Song et al. showed a two-phase collapse mechanism, the first phase being snap-through buckling and subsequent stabilisation of the apex, the second phase being opening of the plastic hinge near the eaves joint after which the frame loses stability and collapses.

Bong (2005), as described by Moss et al. (2009), conducted a three-dimensional (3D) non-linear, elastic-plastic, implicit dynamic finite-element analysis of a portal frame building in fire using the finite-element program Safir. The building was designed in accordance with New Zealand practice (SNZ, 1992, 1997), with the lower half of each column encased in concrete and the top half exposed to fire. In this 3D model, the purlins were also modelled. Similar to Song et al., it was shown that the failure mode of the portal frame was asymmetric. No consideration was given to the column base, which was again assumed to behave as perfectly pinned.

The objective of this paper is to evaluate the existing SCI design method. In this paper, the column base overturning moment $M_{\mathrm{OTM}}$, calculated in accordance with the SCI design method, is assessed using both 2D and 3D non-linear, elastic-plastic, implicit dynamic finite-element analyses. The 2D and 3D finiteelement models are each verified against the results of Song et al. and Moss et al., respectively. A frame similar to the exemplar frame given in the SCI design guide is then modelled, taking into account the limiting strength of the column base, $M_{\mathrm{OTM}}$.

\section{Standard building}

\subsection{Building dimensions}

In the study described in section 6 , both $2 \mathrm{D}$ and $3 \mathrm{D}$ finiteelement models of a single-span building in fire will be considered. This building will be referred to as the 'standard building'. The overall frame dimensions of the standard building are the same as those used for the exemplar frame described in the SCI design guide (Simms and Newman, 2002), shown in Figure 4. As can be seen, the span of each frame is $22.0 \mathrm{~m}$ with a pitch of $6^{\circ}$, and height to the eaves of $5.7 \mathrm{~m}$. The distance between the adjacent frames is $6 \mathrm{~m}$. In the SCI design guide, the columns and rafters are UB $457 \times 152 \times 52$ S275. Since the SCI design guide only considers a $2 \mathrm{D}$ representation, the cold-formed steel sections and spacing used for the purlins and the side rails are not specified. In this paper, it is assumed that the purlins and side

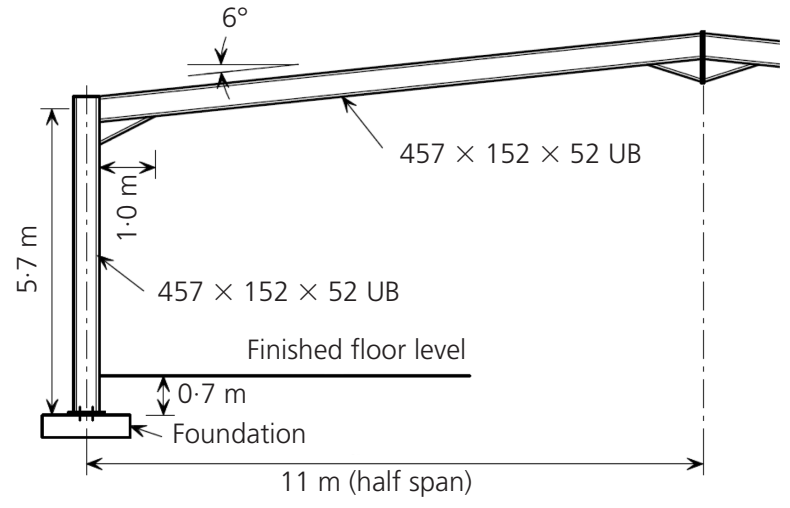

Figure 4. Frame used in SCI worked example (Simms and Newman, 2002)

rails are Steadman 17015 zed sections (Steadmans, 2010) with a yield stress of $390 \mathrm{~N} / \mathrm{mm}^{2}$, spaced at $1500 \mathrm{~mm}$ centres for both columns and rafters.

Figure 5 shows a 2D representation of one of the frames in the standard building considered in this paper. To simplify the model, the haunch is not modelled. It should also be noted that the crosssection properties used for the members are slightly different from those given in standard section property tables. This is because the finite-element program Abaqus used for the analysis is unable to provide default cross-sections with fillets and modelling cross-sections with fillets will immensely increase the computational time. The section properties without fillets are given in Table 1.

As can also be seen from Figure 5, a vertical dead load of $1.0 \mathrm{kN} / \mathrm{m}$ is applied to the frame as a uniformly distributed load. This vertical dead load is consistent with the SCI design guide in which $1.0 \mathrm{kN} / \mathrm{m}$ is also applied including the self-weight of the purlins. In order to be consistent with the SCI design guide, for

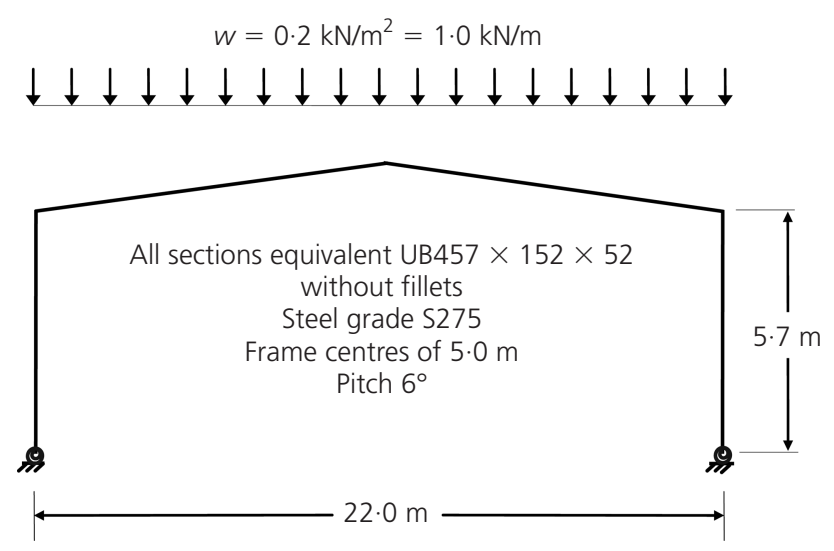

Figure 5. Details of standard frame with rotational spring at column base 


\begin{tabular}{lccrrr}
\hline Section & Area: $\mathrm{cm}^{2}$ & $\begin{array}{c}\text { Yield } \\
\text { strength: } \\
\text { N/mm }\end{array}$ & $I_{\text {maj }}: \mathrm{cm}^{4}$ & $W_{\mathrm{pl}}: \mathrm{cm}^{3}$ & $\begin{array}{r}M_{\mathrm{c}, \mathrm{pl}}: \\
\mathrm{kN} \mathrm{m}\end{array}$ \\
\hline Columns/rafters & $65 \cdot 8$ & 275 & 20969 & 1077 & $296 \cdot 2$ \\
Purlins & 4.52 & 390 & 197 & $19 \cdot 4$ & $5 \cdot 3$
\end{tabular}

Table 1. Properties of equivalent steel sections (without fillets)

used for the standard building

the case of the 2D model, the purlins are not physically modelled. On the other hand, in the 3D model the purlins are modelled and have a self-weight. For the case of the 3D model, therefore, the vertical dead load applied to each frame is reduced to $0.75 \mathrm{kN} / \mathrm{m}$. Both $2 \mathrm{D}$ and $3 \mathrm{D}$ frames, therefore, have the same total vertical dead load.

\subsection{Overturning moment}

For the standard building, according to SCI design method, the value of $M_{\mathrm{OTM}}$ that needs to be resisted is $61.2 \mathrm{kN} \mathrm{m}$. (It should be noted that if this calculation is repeated including the fillets, then the value of $M_{\mathrm{OTM}}$ required reduces to $54 \cdot 2 \mathrm{kN} \mathrm{m}$ ). A value of $M_{\mathrm{OTM}}$ of $61.2 \mathrm{kN} \mathrm{m}$ represents approximately $20 \%$ of the plastic moment capacity of the section, $M_{\mathrm{c}, \mathrm{pl}}$, of $296 \cdot 2 \mathrm{kN} \mathrm{m}$. The SCI method assumes that both the columns and the column bases are fully protected from fire. In reality, when a column is protected from fire with concrete covering, the temperature usually does not rise more than $350^{\circ} \mathrm{C}$, and almost all of the strength of the material is retained. The present authors have run simulations in the past and this has had little effect on the results. It should be noted that the SCI method does not state the rotational stiffness of the column base.

\subsection{Material properties at elevated temperature}

Figure 6 shows engineering stress-strain curves for steel at elevated temperatures ranging from $22^{\circ} \mathrm{C}$ to $1200^{\circ} \mathrm{C}$. In this paper, the temperature of the portal frame will be increased until

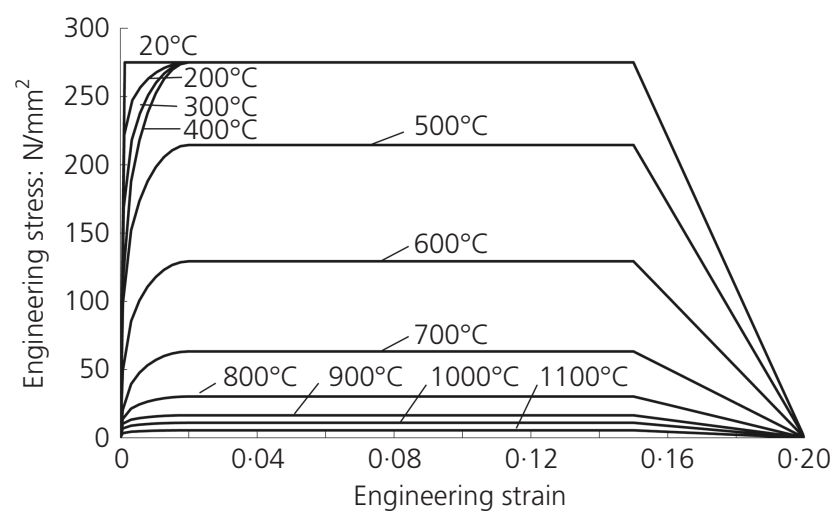

Figure 6. Engineering stress-strain curves for steel grade S275 at different temperatures after Eurocode 3 (BSI, 2005) collapse of the frame. These engineering stress-strain curves are obtained from Eurocode 3 (BSI, 2005). It should be noted that strain-hardening and creep are inherently considered in the stress-strain curves as given by the code.

Figure 7 shows the variation of yield strength and Young's elastic modulus of steel against temperature. The values shown are normalised against their corresponding values at ambient temperature. As can be seen, there is no loss in yield strength for temperatures up to $400^{\circ} \mathrm{C}$; the elastic modulus starts to decrease from $100^{\circ} \mathrm{C}$.

The remaining thermal property required to predict the changed behaviour of the steel structure is the coefficient of thermal expansion. Figure 8 shows this coefficient according to Eurocode 3 . The steel is considered as an isotropic material with a density of $7850 \cdot 0 \mathrm{~kg} / \mathrm{m}^{3}$, as required by dynamic and quasi-static analysis. In this study, the Poisson ratio is taken as $0 \cdot 3$ under fire conditions. Generally, the Poisson ratio is assumed to be independent of temperature (Kaitila, 2002; Zha, 2003).

\section{Fire model}

The ISO834 standard time-temperature curve (Figure 9) is assumed for the combustion of gases that surround the steel frames exposed to fire. Although it is well known that this curve does not represent a practical fire, it is widely used in fire

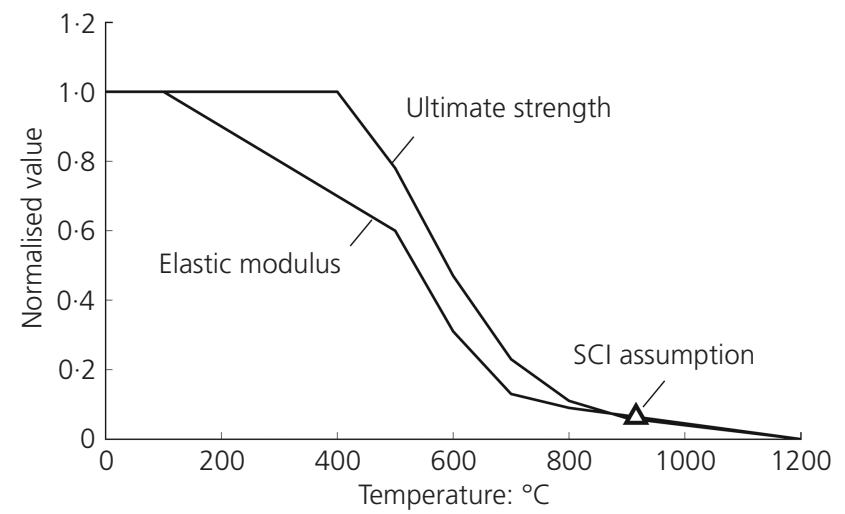

Figure 7. Variation of normalised yield strength and Young's elastic modulus at different temperatures after Eurocode 3 (BSI, 2005) 


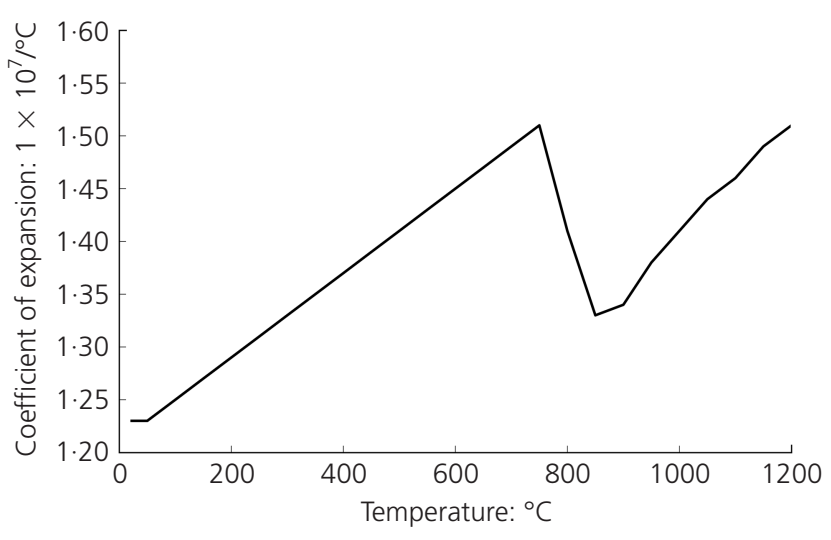

Figure 8. Coefficient of thermal expansion of steel grade S275 at different temperatures after Eurocode 3 (BSI, 2005)

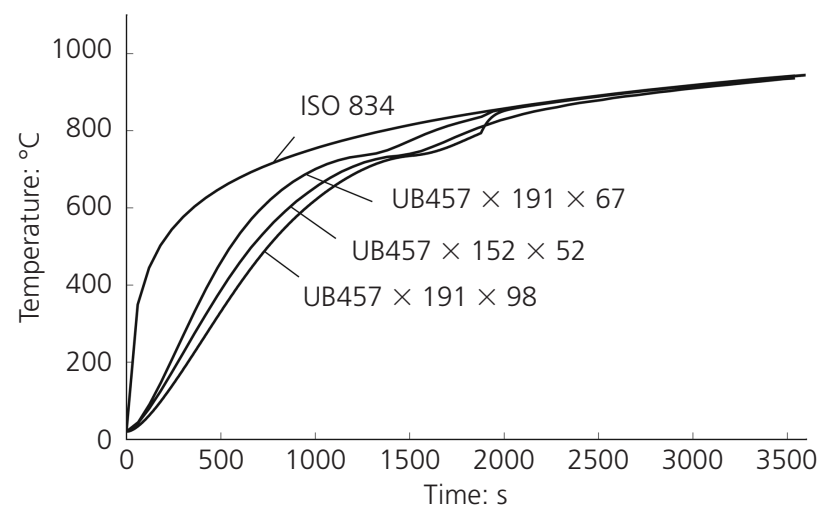

Figure 9. ISO834 standard time-temperature curve (fire curve) and computed Eurocode 3 curve for various sections (BSI, 2005; ISO, 1975)

engineering; the ISO834 curve is also used in the SCI design guide. In this paper, the developed temperature is calculated according to Eurocode 3, based on this standard time-temperature curve, and is applied to the steel section; each steel section has a different associated time-temperature curve.

\section{Finite-element modelling}

\subsection{Finite-element model}

In this paper, the general purpose finite-element program Abaqus (Simulia, 2009) is used for the numerical investigations. Figure 10 shows details of the typical finite-element model. The effect of different number of elements for the column and rafter was investigated in order to provide both accurate results and reduced computation time. It was found that 96 elements were sufficient for the analysis with 16 elements for each column and 32 elements for each half of the rafter for the 2D plane frame model.

The columns and rafters are modelled using beam elements B21 (2D) and B31 (3D). Note that other possible second-order

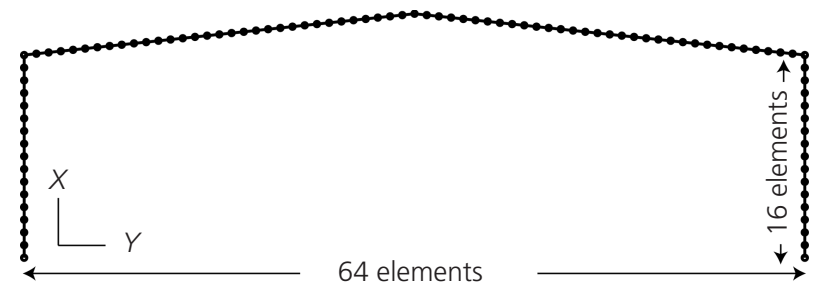

Figure 10. Details of finite-element mesh for 2D frame

elements, for example B22, B32, are avoided owing to the socalled 'volumetric locking' problem, which is induced by the large elemental strain in the deformed configuration. In the numerical models, non-linear stress-strain material curves are modelled. Since the analysis involves large inelastic strains, the engineering stress-strain curve is converted to a true stress and logarithmic plastic strain curve for different temperatures. These true stress and plastic strain data against different temperatures are specified in Abaqus.

Rotational spring elements 'Spring2' are used to model the rotational stiffness of the column bases. Figure 11 shows the two different types of moment-rotation curves that are considered for the column base in this paper: linear and bi-linear with a maximum moment of $M_{\mathrm{OTM}}$.

Song et al. (2009) adopted values for the nominal initial stiffness of the column base, $k_{\mathrm{b}}$, based on the definition of non-dimensional stiffness in Eurocode 3

1. $K_{\mathrm{b}}=k_{\mathrm{b}} /\left(E I_{\text {maj }} / h\right)$

where $k_{\mathrm{b}}$ is the rotational stiffness of the column base, $E I_{\text {maj }}$ is the bending stiffness of the column and $h$ is the height of the column.

Theoretically, a value of $K_{\mathrm{b}}$ of zero is a pinned column base, while a value of infinity corresponds to a fully rigid column base. It should be noted that Song et al. (2009) considered only the case of column bases having linear stiffness and did not cover the case of bi-linear column bases where the strength is limited. In this study, the behaviour of portal frames with bi-linear column bases will be studied.

\subsection{Analysis procedure}

The simulation follows the transient method of analysis to study the behaviour of the portal frame. In this method two simulation steps are considered.

(a) Step 1. Set up the finite-element model and apply a dead load over the rafter while keeping the rafter at ambient temperature, that is $20^{\circ} \mathrm{C}$.

(b) Step 2. Keep the initial loading on the rafter and apply the time-varying elevated temperature to investigate the response of the structure. 


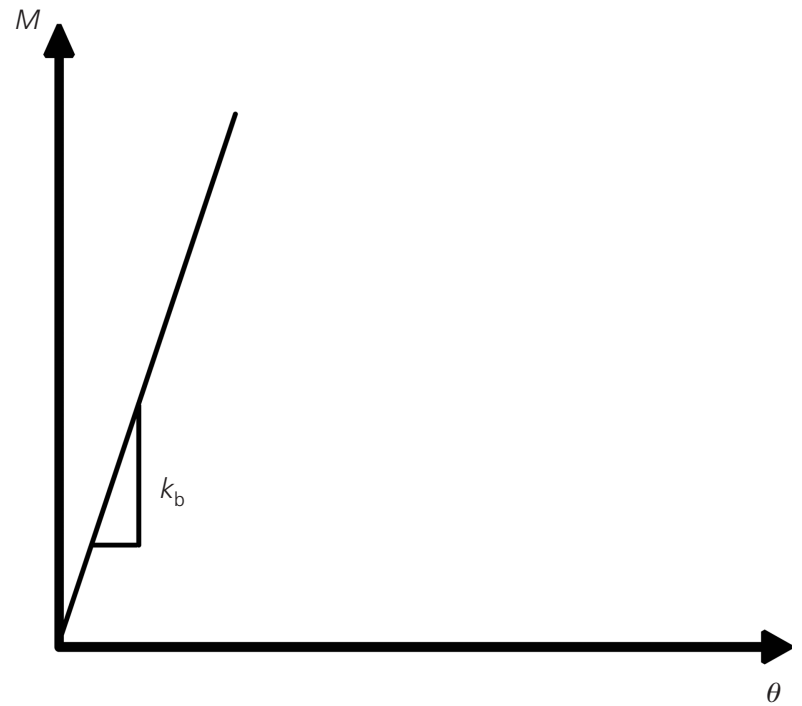

(a)

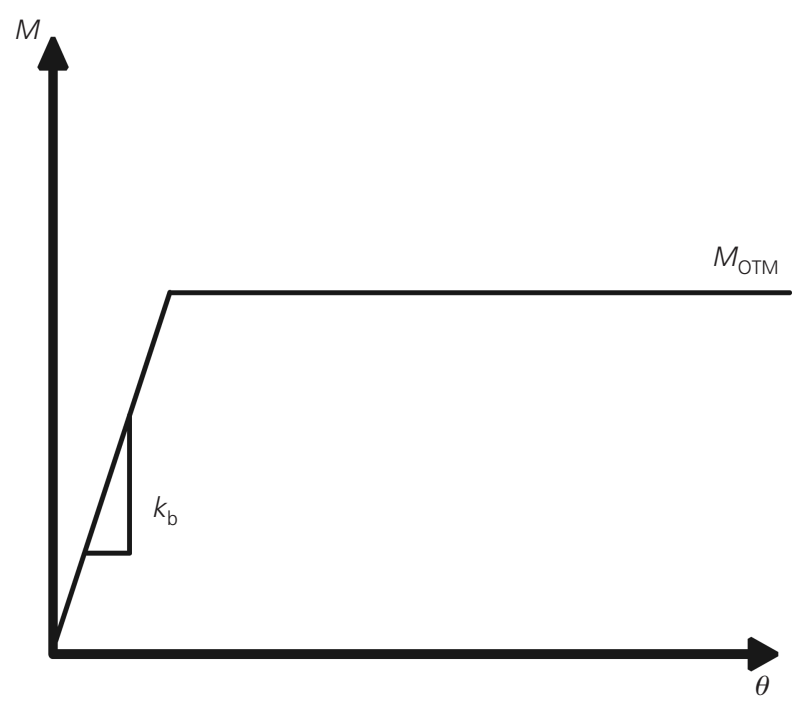

(b)

Figure 11. Moment-rotation curve used for column base

Step 1 is a geometrically non-linear static analysis. This step would provide initial stresses for the whole frame before carrying out the analysis at elevated temperature. Although this step will not involve material non-linearity, as the stresses in the structure are within the elastic limit, the stress-strain curve and temperature curve need to be defined at this step so that they will be automatically activated in the subsequent dynamic step. It was also observed that this step can be carried out without applying any numerical damping.

Step 2 uses implicit dynamic analysis. The reason for choosing dynamic analysis over static analysis is that a static analysis cannot handle the structural instability when the structure starts to snap through, and stops calculation because of the convergence problem. Material non-linearity, geometric non-linearity, inertia forces, structural damping and material stiffness degradation are taken into account in the dynamic analysis, as large displacements and plastic deformations are likely to occur. This step uses an iterative procedure with an automatic incrementation scheme so that the solver determines effective time increments for different iterations, because a fixed time incrementation scheme is slow and can even terminate the calculation, while the material property is highly non-linear. A half-step residual control, Haftol, is used to ensure an accurate dynamic solution. After careful observation, it is found that a combination of Alpha $=-0 \cdot 15$, Haftol $=1 \times 10^{2}$ and the smallest time increment set to $1.0 \times 10^{-15} \mathrm{~s}$ can achieve reasonably fast convergence while not affecting overall accuracy. It is also observed that setting Extrapolation $=$ No and Unsymm $=$ No rapidly accelerates the rate of convergence as well. Rayleigh mass proportional damping is used in this analysis in order to introduce some mechanism to dissipate kinetic energy to obtain quantitatively accurate results in an unstable structure. It can be noted that a value of $5 \%$ Rayleigh mass proportional damping is sufficient.

\section{Validation}

Before carrying out detailed analyses on the standard building, results for both a 2D frame and a 3D model are validated by Abaqus against results reported in the literature. Some additional studies are also carried out in order to draw preliminary conclusions.

\subsection{Two-dimensional model validation}

\subsubsection{Frame description and finite-element idealisation}

In this section, the results of a 2D Abaqus model are compared against that of a model described by Song et al. (2008, 2009). Figure 12 shows details of the single-span portal frame investigated by Song et al. using Vulcan (Table 2). As can be seen, the frame is of span $30 \mathrm{~m}$, height to eaves of $8 \mathrm{~m}$ and height to apex of $8.5 \mathrm{~m}$. The frame is initially loaded through a uniformly distributed vertical load of $5.76 \mathrm{kN} / \mathrm{m}$ on the rafter and a horizontal force of $1.7 \mathrm{kN}$ at the left eaves. The load ratio, a ratio of the applied load in fire to the ultimate load capacity at ambient temperature of the frame, is 0.53 , that is heavily loaded and lower fire resistance. Lower fire resistance means that the frame will collapse much faster.

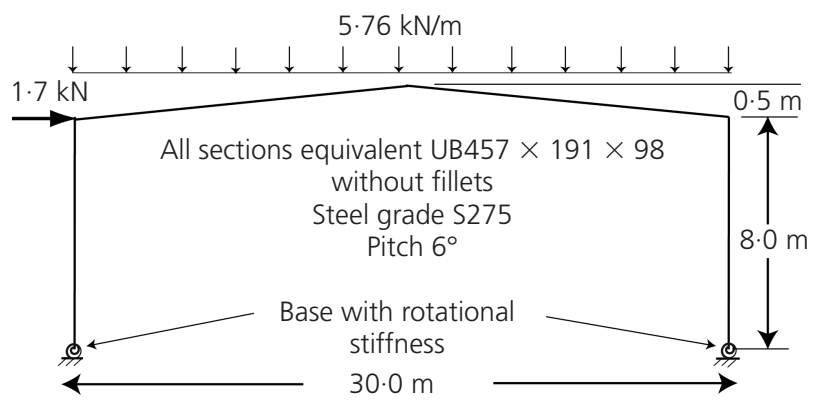

Figure 12. Details of single-span portal frame after Song et al. (2008) 


\begin{tabular}{lccccc}
\hline Section & Area: $\mathrm{cm}^{2}$ & $\begin{array}{c}\text { Yield } \\
\text { strength: } \\
\mathrm{N} / \mathrm{mm}^{2}\end{array}$ & $I_{\text {maj: }}: \mathrm{cm}^{4}$ & $W_{\mathrm{pl}}: \mathrm{cm}^{3}$ & $\begin{array}{c}M_{\mathrm{c}, \mathrm{pl}}: \\
\mathrm{kN} \mathrm{m}\end{array}$ \\
\hline Columns/rafters & 124.4 & 275 & 45700 & 1957 & 538
\end{tabular}

Table 2. Properties of equivalent steel sections used by Song

(2009)

The temperature of the rafters is increased, according the ISO 834 fire curve (ISO, 1975), until the frame collapses. As the columns are protected in fire, they are assumed to remain at ambient temperature throughout the analysis.

For the column base, Song et al. used values of $K_{\mathrm{b}}$ of $0 \cdot 4,2 \cdot 2$ and 4.4 corresponding to cases of nominally pinned, nominally semi-rigid and nominally rigid, respectively, as recommended by Salter et al. (2004).

\subsubsection{Results}

Figures 13, 14 and 15 compare the variation of deflection against temperature with those obtained by Song et al. for the cases of the column base being nominally pinned, semi-rigid and rigid. As can be seen, there is a good agreement between the results obtained using Abaqus and those obtained by Song et al.

Figure 16 compares the deformed shape at different temperatures for the case of the pinned column base against those obtained by Song et al. As can be seen, the mode of collapse is asymmetrical and the deformed shapes are similar.

\subsection{Three-dimensional model validation}

\subsubsection{Frame description and finite-element idealisation} In this section, the results of a 3D Abaqus model are compared against the results of a model labelled as 'case 1' by Moss et al. (2009) and Bong (2005).

Figure 17 shows details of the building considered by Moss et al. As can be seen, the building comprises five frames with purlins running over the rafters of the frame. The building has a span of $30 \mathrm{~m}$, height to eaves of $6.0 \mathrm{~m}$ and a pitch of $7.9^{\circ}$; the distance between adjacent bays is $7.2 \mathrm{~m}$ and the purlins are spaced at $1.5 \mathrm{~m}$. As purlins are susceptible to buckling laterally, bracing channels are provided to all purlins at mid-span. All sections are modelled without fillets, and Table 3 summarises the equivalent section properties.

Unlike the frame described by Song et al., no additional mass was applied to the frame by Moss et al.; instead the frame was modelled to collapse only under its self-weight and the selfweight of the purlins. The equivalent uniformly distributed load is $1.3 \mathrm{kN} / \mathrm{m}$. This corresponds to a load ratio of 0.21 and 0.18 for pinned and fixed column bases, respectively; such a load ratio is

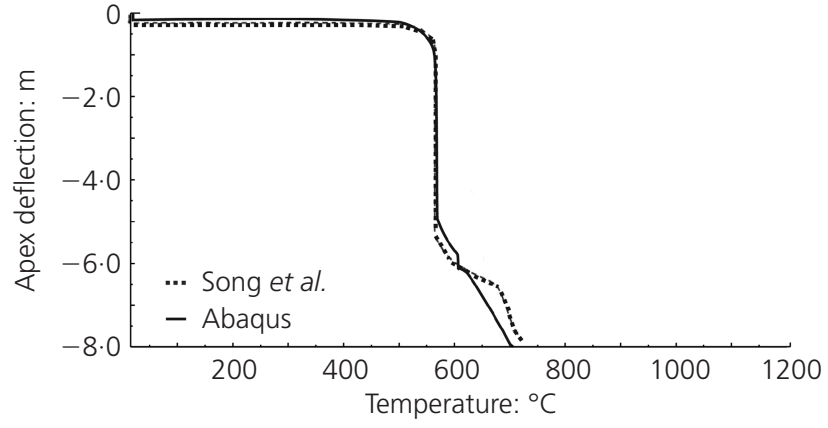

(a)

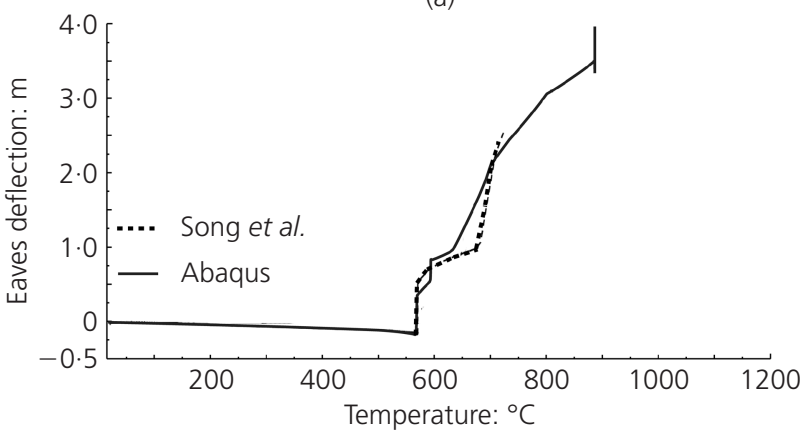

(b)

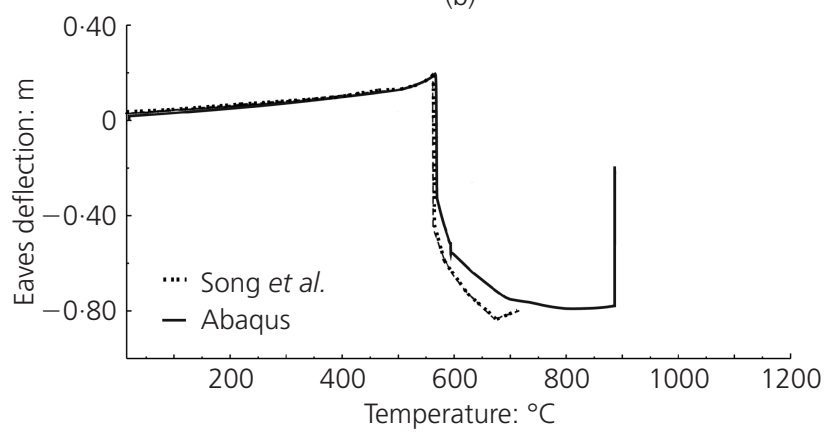

(c)

Figure 13. Variation of deflection against temperature for singlespan portal frame when column base is nominally pinned $\left(K_{b}=0.4\right)$ after Song et al. (2008): (a) apex; (b) left eaves; (c) right eaves

more reasonable for a building. A lower load ratio gives higher fire resistance.

Figure 18 shows details of the building idealisation. All sections are modelled in Abaqus using B31 beam elements. As can be 


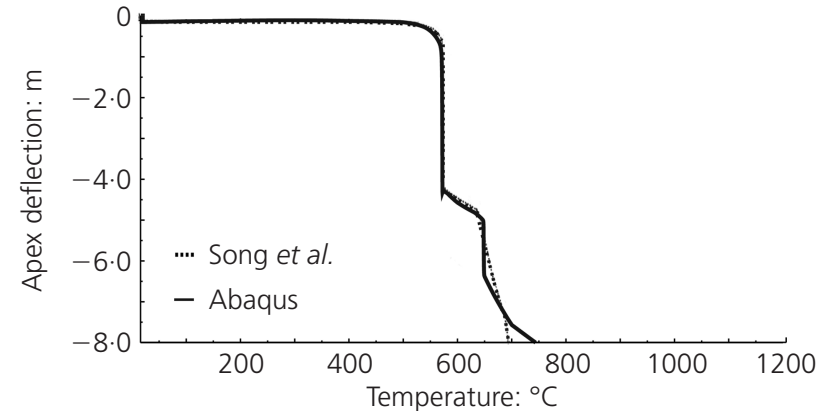

(a)

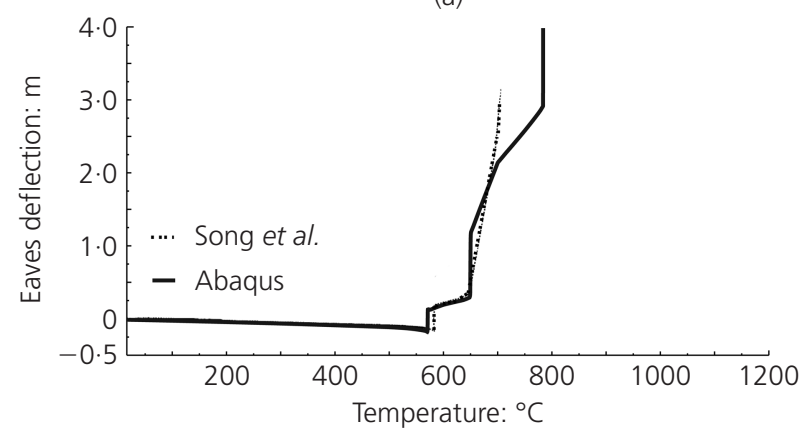

(b)

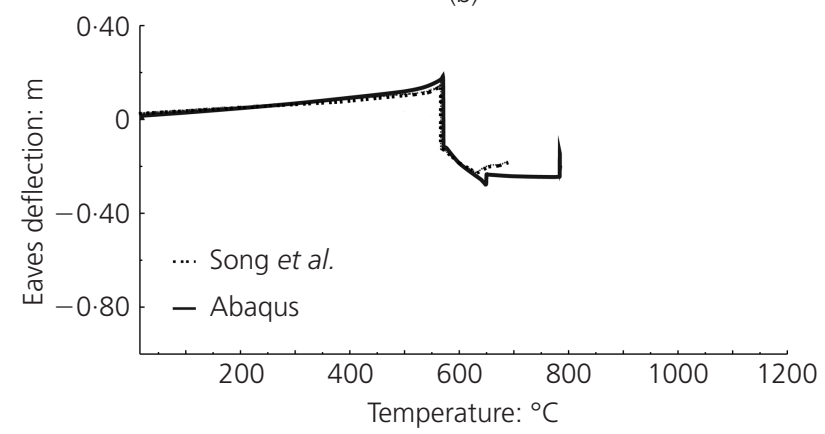

(c)

Figure 14. Variation of deflection against temperature for singlespan portal frame when column base is nominally semi-rigid $\left(K_{b}=2 \cdot 2\right)$ after Song et al. (2008): (a) apex; (b) left eaves; (c) right eaves

seen, the ends of the purlins are restrained in the global $X$ and $Y$ directions, transverse to the direction of the purlins running along the length of the building. The purlins are not restrained in their axial direction. Each frame is restrained laterally in the out-ofplane direction at three positions: mid-height of columns, top of columns and apex.

Figure 19 shows details of the connection between the purlins and rafters. The connection is pinned in all directions other than the on-plan plane of the roof, where the connection was continuous. In Abaqus, this connection constraint is achieved by using MPC PIN parameters. MPC defines multi-point constraints between different degrees of freedom of the model, and PIN provides a pinned joint between two nodes, so MPC PIN makes the displacements equal but leaves the rotations independent of each other. It should be noted that for the frame and loading

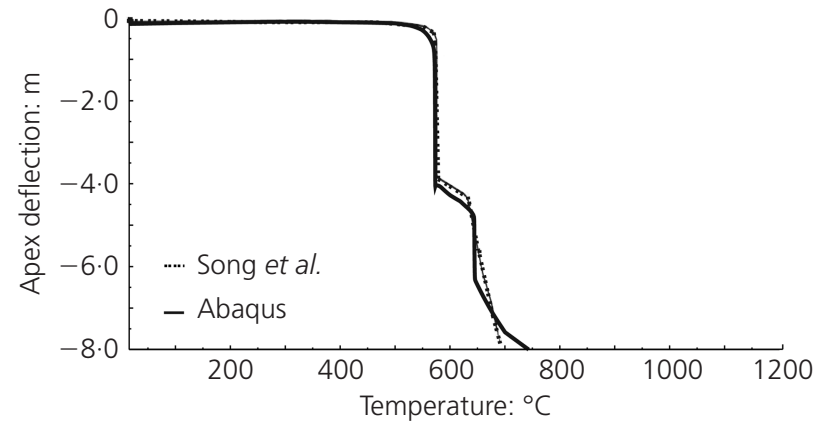

(a)

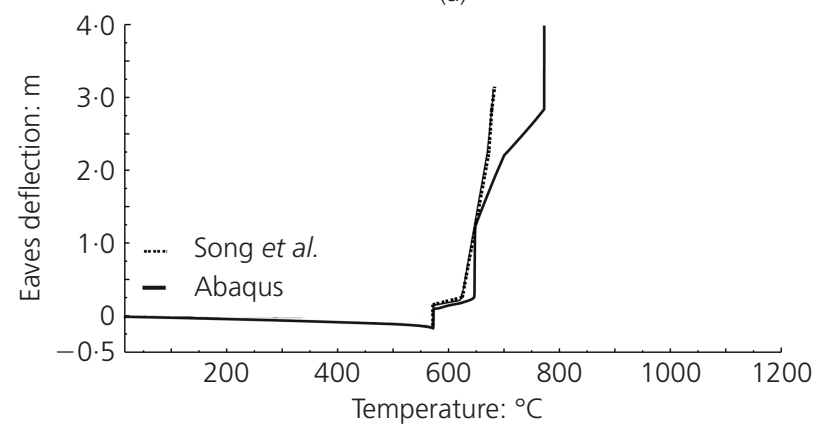

(b)

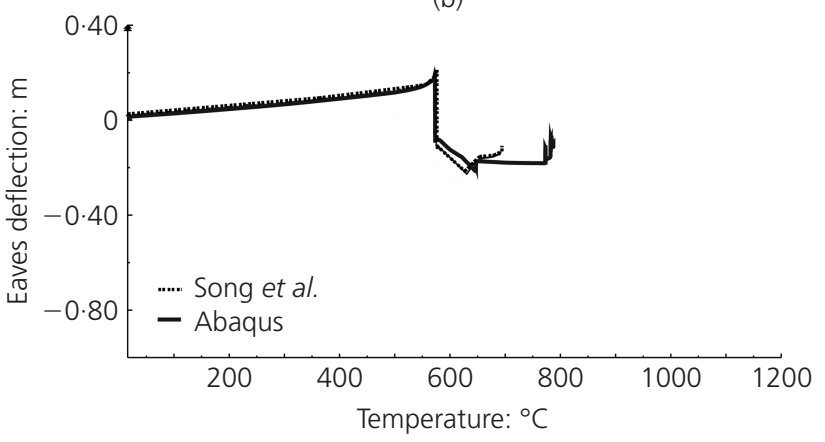

(c)

Figure 15. Variation of deflection against temperature for single span portal frame when column base is nominally rigid $\left(K_{b}=4 \cdot 4\right)$ after Song et al. (2008): (a) apex; (b) left eaves; (c) right eaves

conditions considered in this paper, little difference has been noted in the graphs of deflection against temperature, whether the connections had been pinned in all directions or rigid in all directions.

\subsubsection{Fire location}

Moss et al. considered various fire scenarios. For the purpose of validation, only the scenario where a fully developed fire is applied to the middle frame of the structure is considered.

\subsubsection{Results}

Figure 20 shows the variation of apex deflection against temperature for the cases considered by Moss et al. when fire is imposed in the whole structure. Figure 21 compares the collapsed shape of the buildings. As can be seen, there is a good agreement between the results obtained using Abaqus and that reported by Moss et al. 


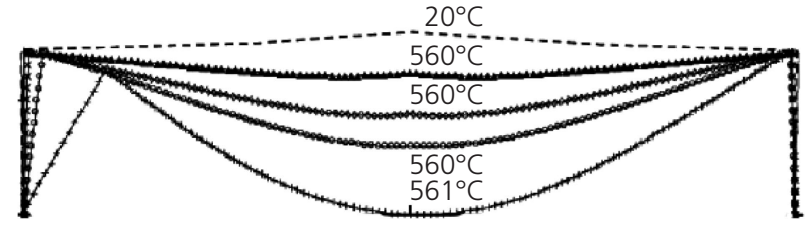

(a)

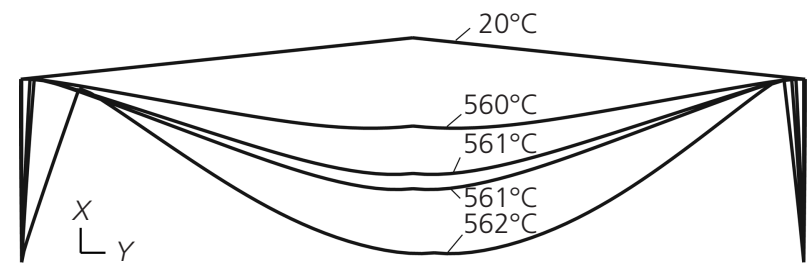

(b)

Figure 16. Comparison of deformed shape for a standard frame having pinned column base after Song et al. (2008): (a) Song et al. (2008); (b) Abaqus

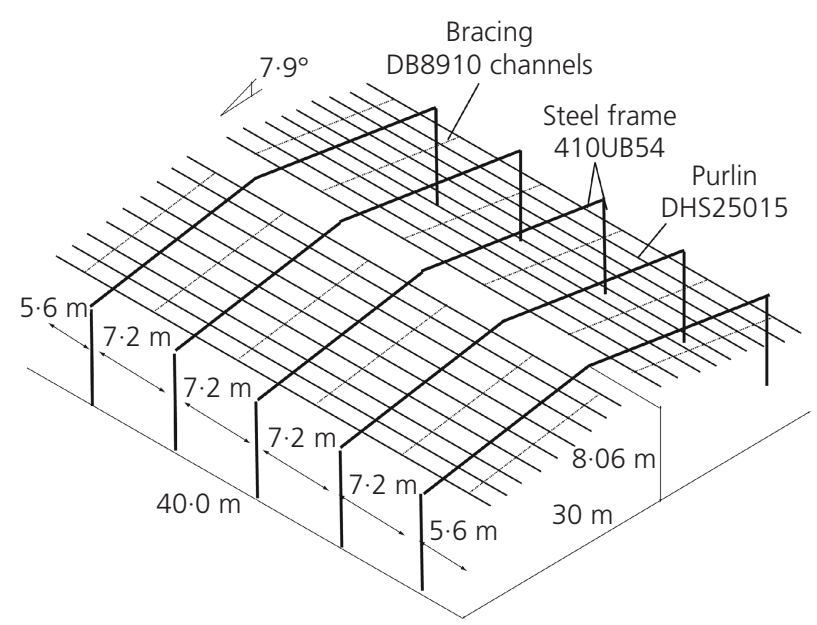

Figure 17. Details of the building considered by Moss et al. (2009) and Bong (2005)

\section{Study on standard building}

In the previous sections, both 2D and 3D Abaqus models were validated against different models described in the literature. For

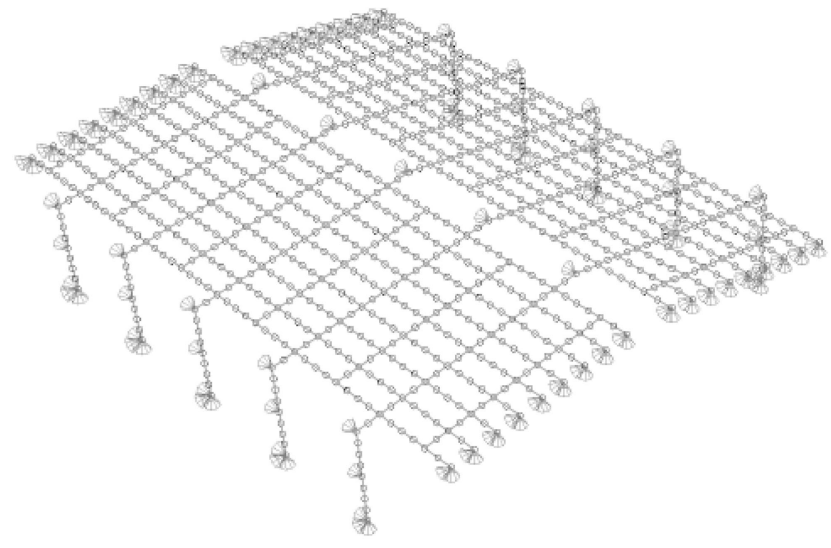

Figure 18. Details of the frame idealisation with restraints of the portal frame by Moss et al. (2009) and Bong (2005)

a building in fire boundary conditions, the behaviour of a $2 \mathrm{D}$ plane frame model, in which no restraint is provided by the purlins (or side rails), can be considered as being a lower bound solution. On the other hand, a 3D model having an infinite number of frames, in which only the centre frame and purlins connected to the central frame are modelled in fire, can be considered as being an upper bound solution.

In this section, four different fire scenarios will be considered for the standard building, denoted by fire scenarios A, B, C and D, representing one, three, five and all frames in fire, respectively.

Figure 22 shows details of the frames and purlins in fire for fire scenarios A, B and C. As can be seen, the purlins adjacent to the frames in fire are also modelled at elevated temperature. For the case of fire scenario A (see Figure 22(a)), the model adopted is similar to that described in the section 5.2, with five frames modelled, of which the middle frame is modelled at elevated temperatures; there are, therefore, two frames on either side of the central frame in fire with purlins providing restraint. Although an infinite number of frames on either side would be the true upper bound solution, in the interest of computational efficiency and after carrying out a series of preliminary simulations, it has been found that two are sufficient.

\begin{tabular}{lccccc}
\hline Section & Area: $\mathrm{cm}^{2}$ & $\begin{array}{c}\text { Yield } \\
\text { strength: } \\
\mathrm{N} / \mathrm{mm}^{2}\end{array}$ & $I_{\text {maj: }}: \mathrm{cm}^{4}$ & $W_{\mathrm{pl}}: \mathrm{cm}^{3}$ & $\begin{array}{c}M_{\mathrm{c}, \mathrm{pl}}: \\
\mathrm{kN} \mathrm{m}\end{array}$ \\
\hline Columns/rafters & $67 \cdot 8$ & 275 & 1672 & 249 & 68.4 \\
Purlins & $6 \cdot 2$ & 275 & 583 & 69 & 19 \\
Bracing & 4.0 & 275 & 22 & 5.8 & 1.6
\end{tabular}

Table 3. Properties of equivalent steel sections used by Moss et al. 


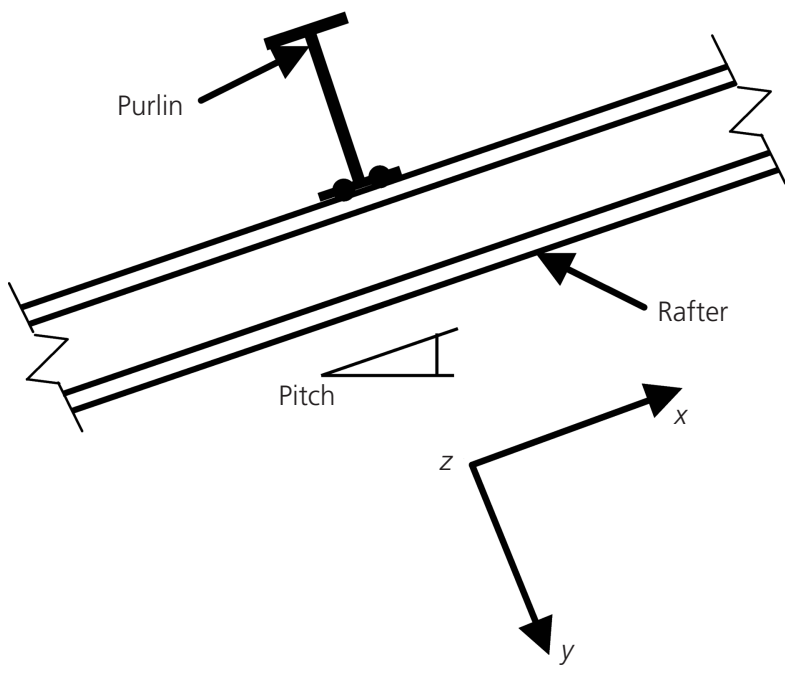

(a)

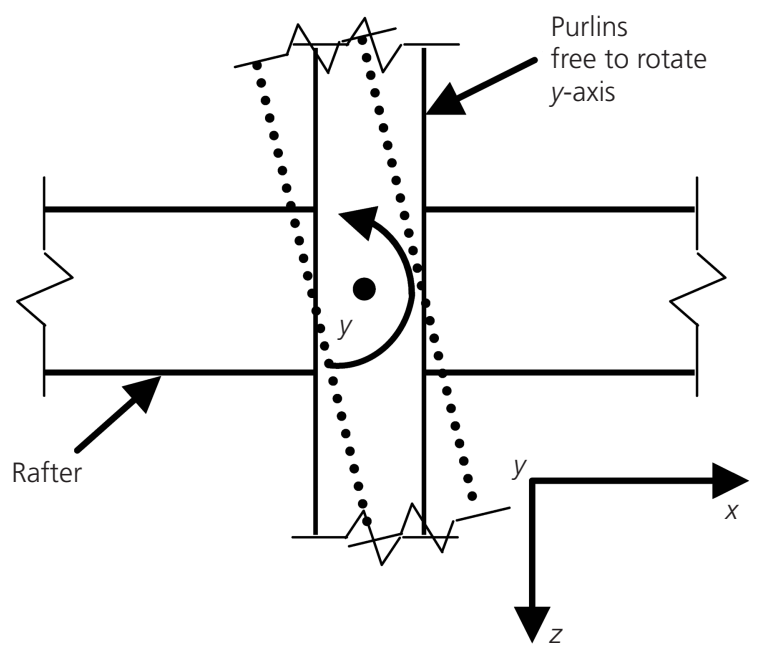

(b)

Figure 19. Details of connection between purlins and rafters as used by Moss et al. (2009) and Bong (2005): (a) side view; (b) plan view

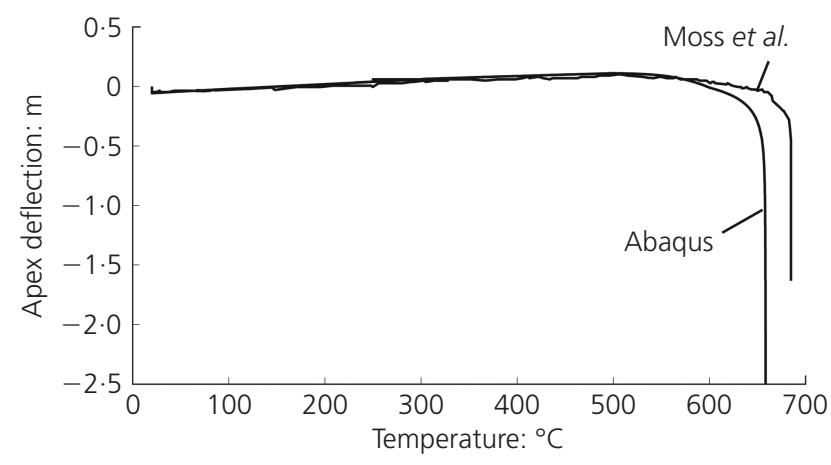

Figure 20. Validation of model after Moss et al. (2009) and Bong (2005)

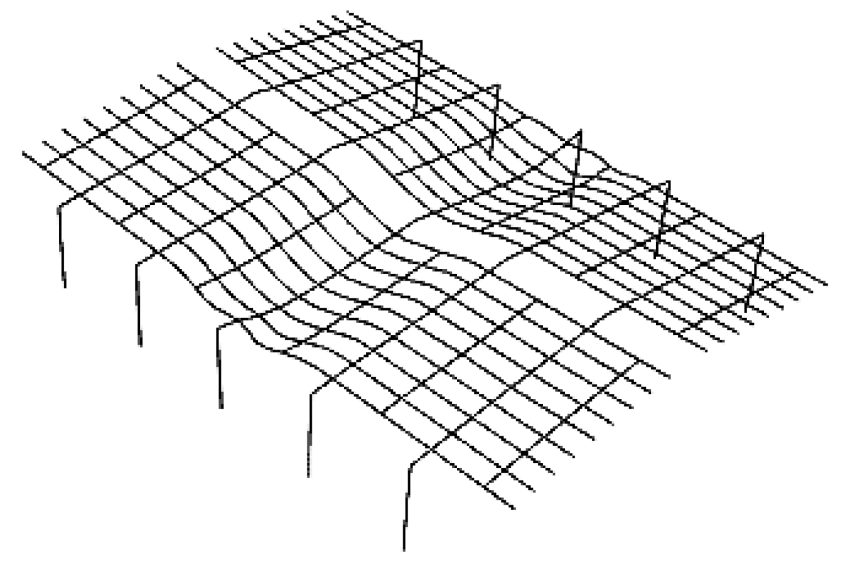

(a)

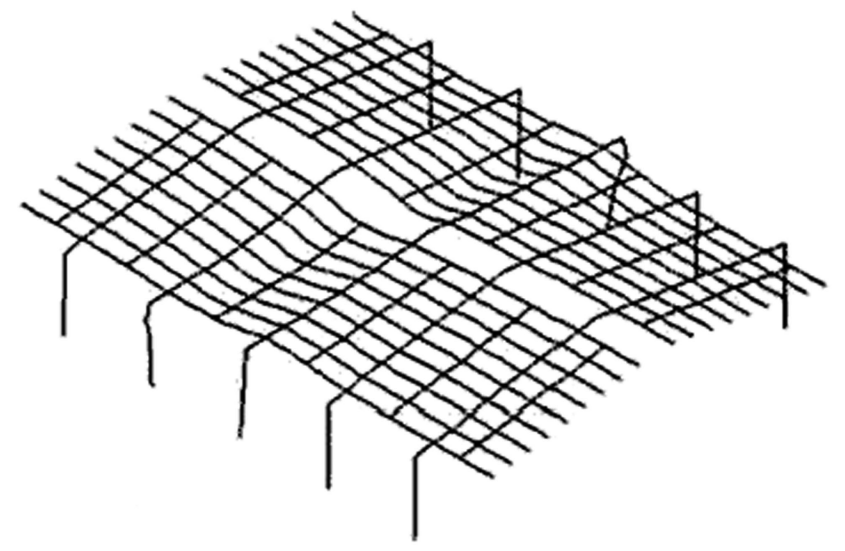

(b)

Figure 21. Comparison of collapsed building shape: (a) collapsed shape from Abaqus; (b) collapsed shape after Moss et al. (2009)

For the case of fire scenario B (see Figure 22(b)), in order to keep the amount of restraint provided by the purlins the same as that of fire scenario A, with two frames at both ends providing restraint, seven frames are modelled, of which the middle three are in fire. Similarly, for the case of fire scenario C (see Figure 22(c)), nine frames are modelled. Fire scenario D, considering all frames in fire with no restraint provided by the purlins, is idealised using the 2D plane frame model (see Figure 22(d)).

In this section, the effect of different column base moment rotation curves is investigated for each of the fire scenarios described above.

\subsection{Behaviour of building of perfectly-pinned column bases}

Figure 23 shows the variation of deflection against temperature for the standard building for each of the four fire scenarios. In all cases, the column bases are perfectly pinned. The deformed shape for fire scenarios A and D are shown in Figure 24, and the results are summarised in Table 4. As can be seen, for fire scenario A, 


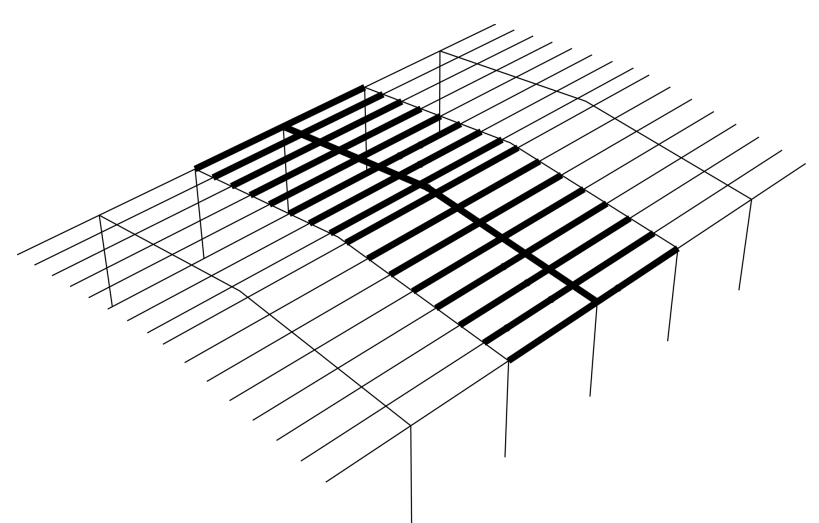

(a)

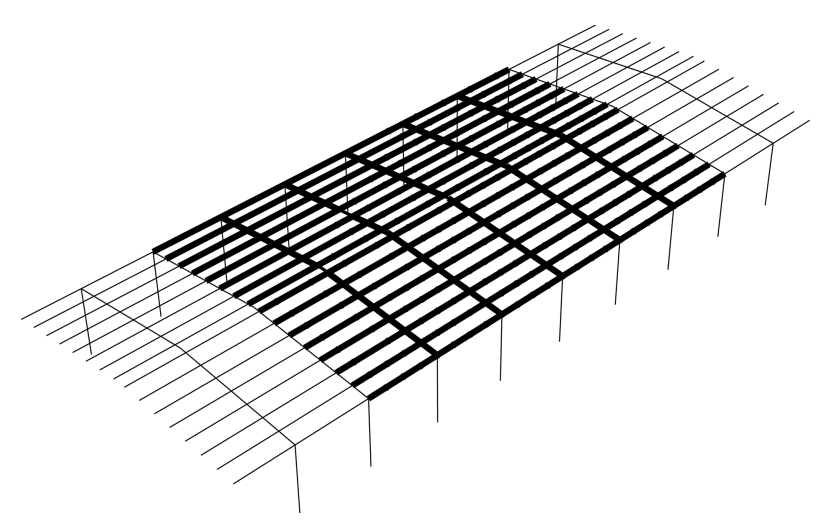

(c)

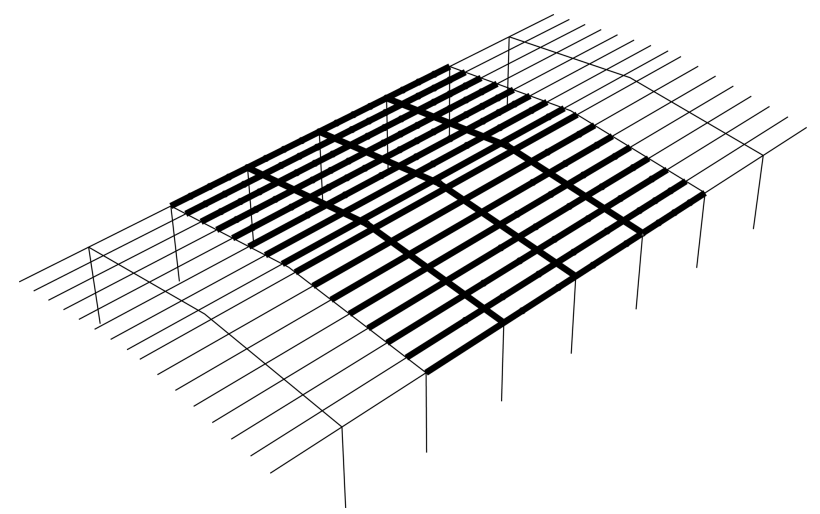

(b)

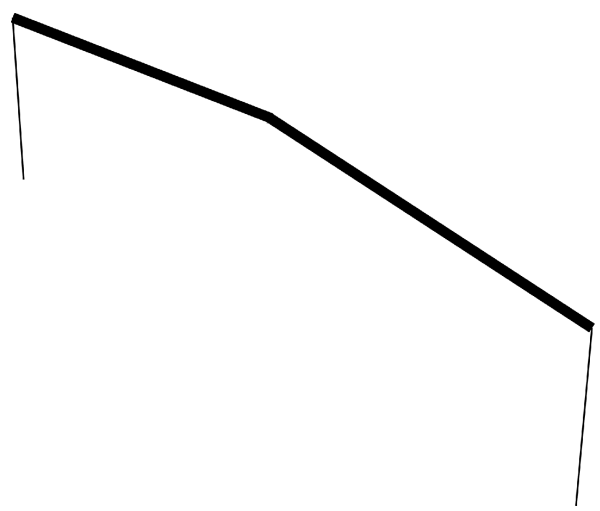

(d)

Figure 22. Different fire scenarios (note: bold line indicates members in fire and thin line indicates member at ambient temperature): (a) fire scenario $A$ : (b) fire scenario $B$; $(c)$ fire scenario $C$; (d) fire scenario D

the rafters remain suspended below the columns throughout the duration of fire due to catenary action of purlin; the building has, therefore, not collapsed up to a temperature of $1100^{\circ} \mathrm{C}$.

From Table 4 it can be seen that the snap-through-buckling temperature decreases only slightly, from $822^{\circ} \mathrm{C}$ for fire scenario B to a temperature of $809^{\circ} \mathrm{C}$ for fire scenario D. It should be noted, however, that the change in collapse temperature is larger, decreasing from $1039^{\circ} \mathrm{C}$ to $811^{\circ} \mathrm{C}$. While these temperatures are similar to the maximum temperature of $890^{\circ} \mathrm{C}$ assumed by the SCI design method, for all fire scenarios the outward rotations of the columns are much higher than the $1^{\circ}$ specified by the SCI design method.

Using Wong's (2001) method for calculating the snap-throughbuckling temperature, it was shown that the snap-through-buckling temperature was $709^{\circ} \mathrm{C}$.

\subsection{Effect on building of linear column base stiffness}

As discussed in section 4.2, the SCI design method does not provide values for the rotational stiffness, $K_{\mathrm{b}}$, of the column base
Song et al. (2008) used values of $K_{\mathrm{b}}$ of $0 \cdot 4,2 \cdot 2$ and $4 \cdot 4$, corresponding to cases of nominally pinned, nominally semi-rigid and nominally rigid, respectively.

For the lower bound fire scenario D, Figure 25 shows the variation of deflection against temperature for different column base rotational stiffness. The results for the perfectly pinned and perfectly rigid column bases are also shown in Table 5.

As can be seen from Figure 25 and Table 5, the snap-throughbuckling temperature increases from $809^{\circ} \mathrm{C}$ for the perfectly pinned column base to $936^{\circ} \mathrm{C}$ for the perfectly rigid column base. Unlike the case of the perfectly pinned column base, the twophase collapse mechanism discussed by Song can clearly be seen.

From Table 5, for the nominally pinned column base, the outward and inward eaves rotation at the top of the columns is $1.7^{\circ}$ and $2 \cdot 3^{\circ}$. These values are only slightly larger than the $1^{\circ}$ specified by the SCI design method. 


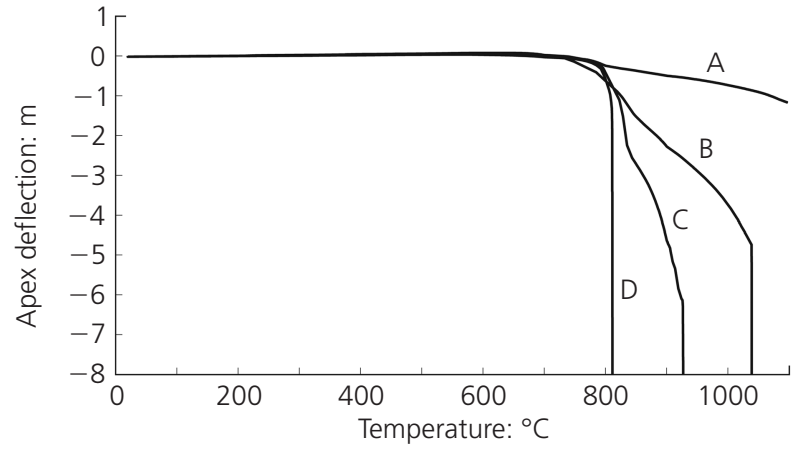

(a)

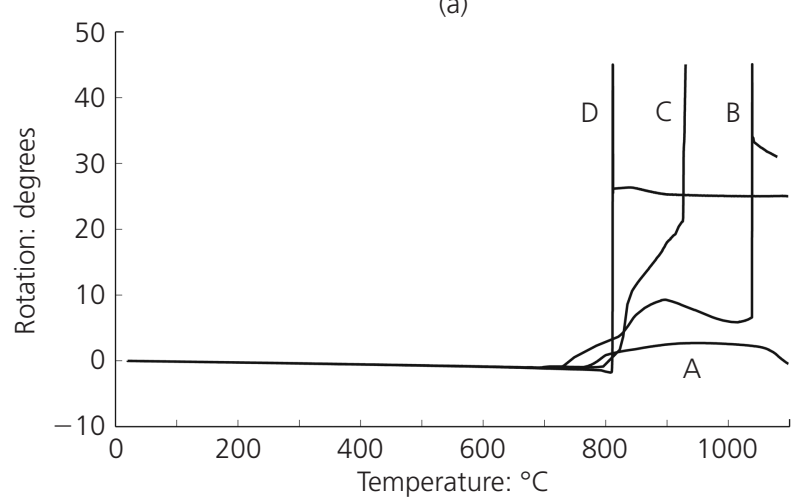

(b)

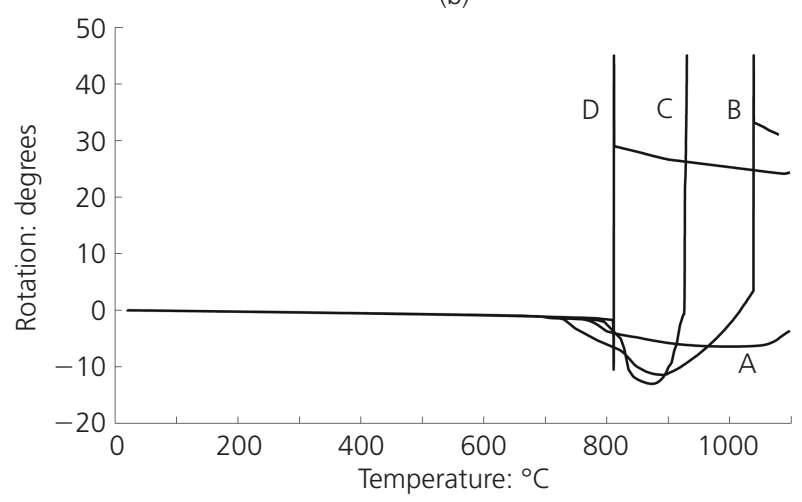

(c)

Figure 23. Variation of deflection against temperature for standard building with perfectly pinned column bases: (a) apex deflection; (b) left eaves rotation: (c) right eaves rotation

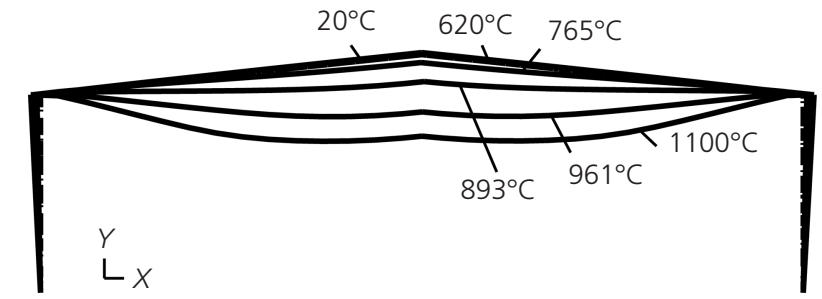

(a)

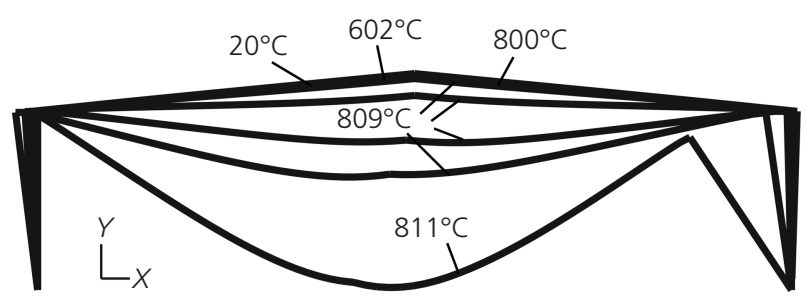

(b)

Figure 24. Deformed shape for standard building with pinned column bases for two fire scenarios: (a) fire scenario $A$; (b) fire scenario $D$

\subsection{Effect on building of partial strength column base stiffness}

\subsection{1 $M_{\mathrm{OTM}}$ of $M_{\mathrm{SCl}}$}

In section 2.1 it was stated that, in accordance with the SCI design method, the column base needs only be designed to sustain an overturning moment, $M_{\mathrm{OTM}}$, of $61.2 \mathrm{kN} \mathrm{m}$. Such an overturning moment represents approximately $20 \%$ of the plastic moment capacity of the section.

Figure 26 shows the variation of deflection against temperature for fire scenario D for three different column base rotational stiffnesses having a partial strength $M_{\mathrm{OTM}}$ of $61.2 \mathrm{kN} \mathrm{m}$. The results are summarised in Table 6 .

As can be seen from Table 6, for all three different column base rotational stiffnesses, the snap-through-buckling temperature is $818^{\circ} \mathrm{C}$, only slightly higher than $809^{\circ} \mathrm{C}$ for the pinned support. The effect of the partial strength column base means that the

\begin{tabular}{lccc}
\hline Fire scenario & $\begin{array}{c}\text { Snap-through- } \\
\text { buckling } \\
\text { temperature: }{ }^{\circ} \mathrm{C}\end{array}$ & $\begin{array}{c}\text { Collapse } \\
\text { temperature: }{ }^{\circ} \mathrm{C}\end{array}$ & $\begin{array}{c}\text { Maximum outward } \\
\text { column rotation by } \\
890^{\circ} \mathrm{C}: \text { degrees }\end{array}$ \\
\hline A & $>1100$ & $>1100$ & $0 \cdot 56$ \\
B & 822 & 1039 & $9 \cdot 1$ \\
C & 810 & 926 & $12 \cdot 0$ \\
D & 809 & 811 & Collapsed
\end{tabular}

Table 4. Summary of behaviour of standard building with pinned column base 


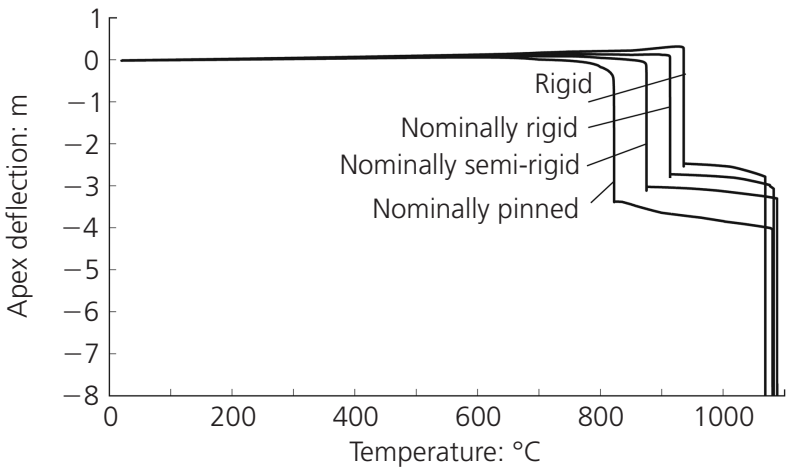

(a)

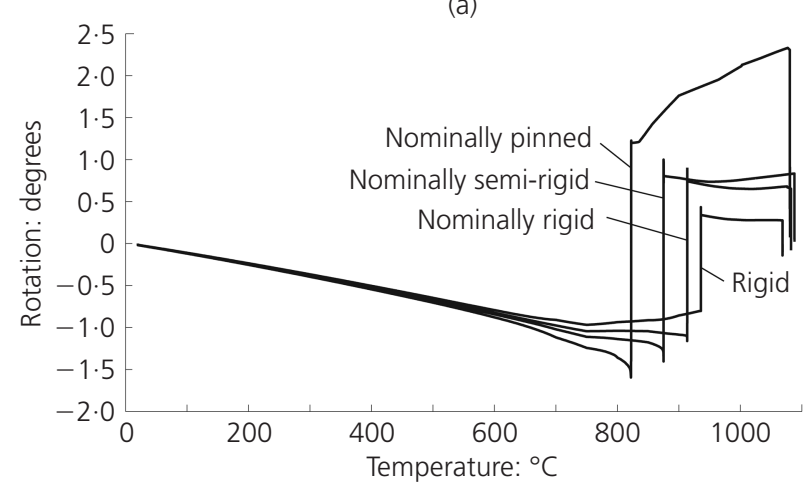

(b)

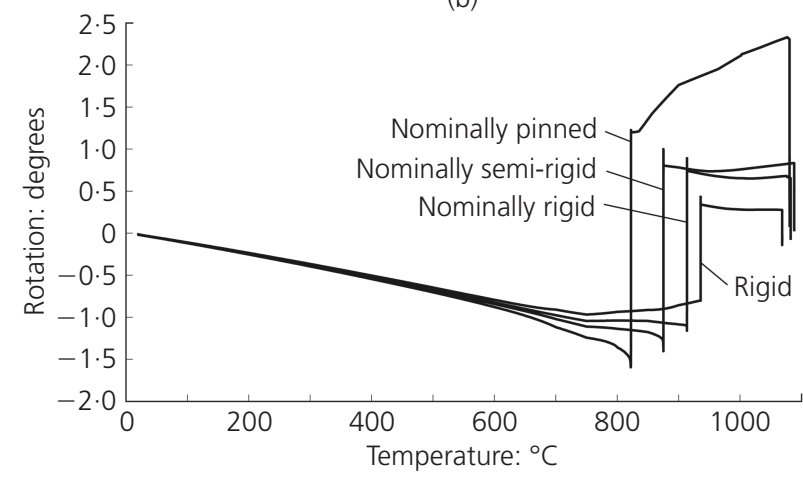

(c)

Figure 25. Variation of deflection and eaves rotation against temperature for standard building analysed as a 2D plane frame with linear column base: (a) apex deflection; (b) left eaves rotation; (c) right eaves rotation

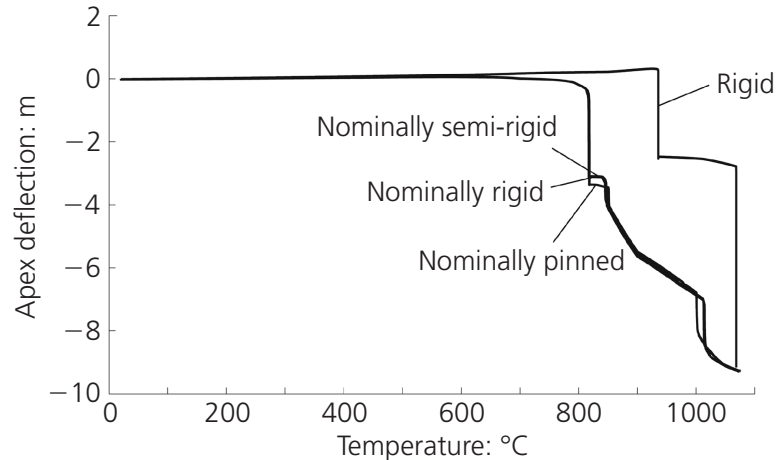

(a)

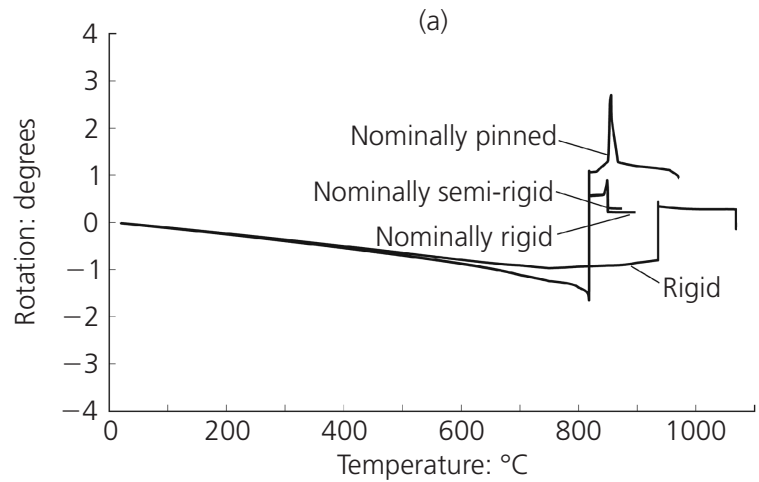

(b)

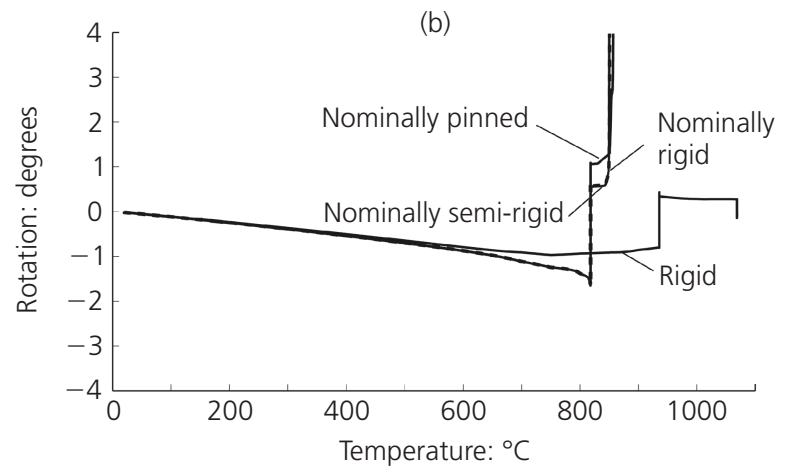

(c)

Figure 26. Variation of deflection and eaves rotation against temperature for standard building analysed as a 2D plane frame (fire scenario D) with column base having a value of $M_{\mathrm{OTM}}$ of $\mathrm{MSCl}_{\mathrm{SC}}$ (61.2 kN m) with different base rigidity: (a) apex deflection: (b) left eaves rotation; (c) right eaves rotation

\section{Column base stiffness}

\section{Maximum outward \\ Maximum inward column rotation by column rotation by $890^{\circ} \mathrm{C}$ : degrees $890^{\circ} \mathrm{C}$ : degrees}

\begin{tabular}{|c|c|c|c|c|}
\hline Pinned & 809 & 811 & $14 \cdot 1$ & Collapsed \\
\hline Nominally pinned & 822 & 1082 & $1 \cdot 7$ & $2 \cdot 3$ \\
\hline Nominally semi-rigid & 875 & 1082 & 1.4 & 0.8 \\
\hline Nominally rigid & 914 & 1082 & $1 \cdot 4$ & $0 \cdot 7$ \\
\hline Rigid & 936 & 1069 & $1 \cdot 0$ & $0 \cdot 3$ \\
\hline
\end{tabular}

Table 5. Summary of behaviour of standard building under fire scenario $D$ with column base having linear stiffness 


\begin{tabular}{|c|c|c|c|c|c|}
\hline \multirow[t]{2}{*}{ Column base stiffness } & \multirow{2}{*}{$\begin{array}{l}\text { Snap-through- } \\
\text { buckling } \\
\text { temperature: }{ }^{\circ} \mathrm{C}\end{array}$} & \multirow[t]{2}{*}{$\begin{array}{c}\text { Collapse } \\
\text { temperature: }{ }^{\circ} \mathrm{C}\end{array}$} & \multirow{2}{*}{$\begin{array}{l}\text { Maximum outward } \\
\text { column rotation by } \\
890^{\circ} \mathrm{C} \text { : degrees }\end{array}$} & \multicolumn{2}{|c|}{$\begin{array}{c}\text { Maximum inward } \\
\text { column rotation: degrees }\end{array}$} \\
\hline & & & & By $890^{\circ} \mathrm{C}$ & By $1000^{\circ} \mathrm{C}$ \\
\hline Nominally pinned & 818 & 869 & $1 \cdot 7$ & Collapsed & Collapsed \\
\hline Nominally semi-rigid & 818 & 879 & $1 \cdot 7$ & Collapsed & Collapsed \\
\hline Nominally rigid & 818 & 1010 & $1 \cdot 7$ & $14 \cdot 0$ & $16 \cdot 5$ \\
\hline
\end{tabular}

Table 6. Summary of behaviour of standard building under fire scenario $D$ having a value of Mотм of $61 \cdot 2 \mathrm{kN}$ m with column base having linear stiffness

frame behaves similarly to that of a frame with a perfectly pinned column base. Increasing the column base rotational stiffness from nominally pinned to either nominally semi-rigid or nominally rigid has very little effect. The maximum outward column rotation is $1.7^{\circ}$.

Figure 27 shows the same results for fire scenarios A, B and C; the results are summarised in Table 7. As can be seen, for fire scenario $\mathrm{A}$, the building remains stable and suspended throughout the duration of the fire. For fire scenarios B and C, the frame undergoes snap-through-buckling at temperatures of $828^{\circ} \mathrm{C}$ and $818^{\circ} \mathrm{C}$, respectively. These temperatures are only slightly higher than that of fire scenario $\mathrm{D}$ of $811^{\circ} \mathrm{C}$. For fire scenario $\mathrm{D}$, the building collapses after snap-through buckling. In all cases, the maximum outward eaves rotation by $890^{\circ} \mathrm{C}$ is $1.7^{\circ}$; the inwards rotation is $34 \cdot 1^{\circ}$.

\subsection{2 $\mathrm{M}_{\mathrm{OTM}}$ of $2 \mathrm{MSCl}$}

Figure 28 shows the variation of deflection against temperature for the standard building for the case of a nominally pinned column base with the overturning moment limited to $M_{\mathrm{OTM}}$ of $2 M_{\mathrm{SCI}}$, that is $122.4 \mathrm{kN} \mathrm{m}$. The results are summarised in Table 8 . As can be seen, the inward rotation for the frame of fire scenario $\mathrm{D}$ at $890^{\circ} \mathrm{C}$ is $3.25^{\circ}$ as opposed to the columns collapsing. Figure 29 shows the effect of increasing the overturning moment on the variation of frame deflection against temperature.

\section{Parametric study}

\subsection{Introductory remarks}

In the previous sections, it was shown that that the finite-element model can reproduce similar results to those reported in the literature for both a 2D frame and a 3D building. For the standard building, it was also shown that if the number of frames in fire can be taken into account, then the collapse temperature will increase and the column rotations will decrease.

In this section, a parametric study will be undertaken using the lower bound 2D plane frame. The results will be compared against the criterion assumed by the SCI design guidance, that at $890^{\circ} \mathrm{C}$ the columns will not have exceeded a rotation of $1^{\circ}$ from the vertical.

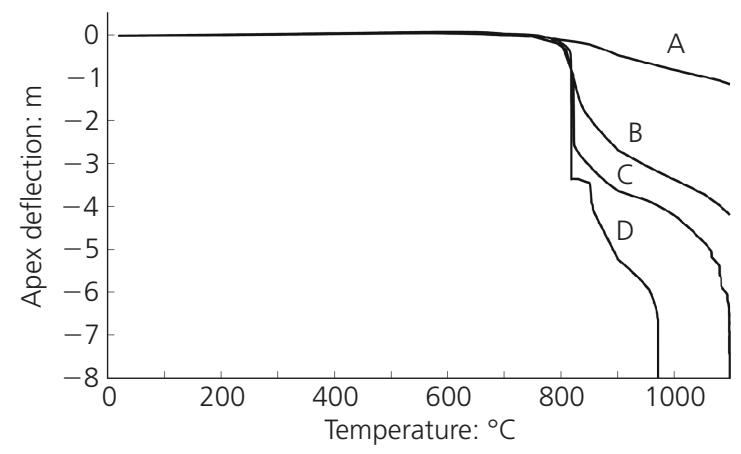

(a)

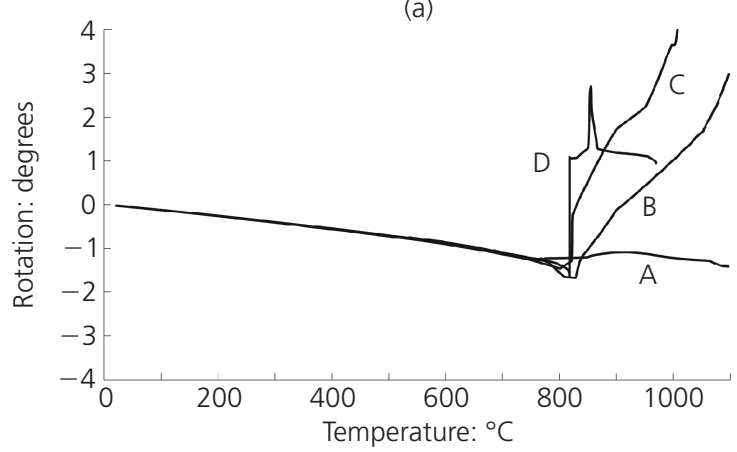

(b)

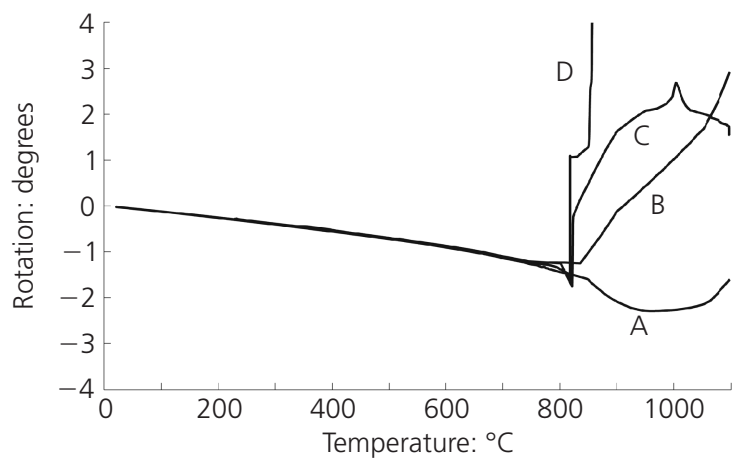

(c)

Figure 27. Variation of deflection and eaves rotation against temperature for standard building with nominally pinned partialstrength column base having a value of $M_{\text {OTM }}$ of $M_{S C I}(61.2 \mathrm{kN} \mathrm{m})$ for different fire scenarios: (a) apex deflection: (b) left eaves rotation; (c) right eaves rotation 


\begin{tabular}{lcrcc}
$\begin{array}{l}\text { Fire } \\
\text { scenario }\end{array}$ & $\begin{array}{c}\text { Snap-through- } \\
\text { buckling } \\
\text { temperature: }{ }^{\circ} \mathrm{C}\end{array}$ & $\begin{array}{c}\text { Collapse } \\
\text { temperature: } \\
{ }^{\circ} \mathrm{C}\end{array}$ & $\begin{array}{c}\text { Maximum outward Maximum inward } \\
\text { column rotation by } \\
890^{\circ} \mathrm{C} \text { : degrees }\end{array}$ & $\begin{array}{c}\text { column rotation } \\
\text { by } 890^{\circ} \mathrm{C} \text { : degrees }\end{array}$ \\
\hline A & n/a & $>1100$ & $2 \cdot 3$ & 0.40 \\
B & 828 & $>1100$ & $1 \cdot 7$ & $2 \cdot 49$ \\
C & 818 & $>1100$ & 1.8 & 3.23 \\
D & 818 & 869 & Collapsed & Collapsed
\end{tabular}

Table 7. Summary of behaviour of standard building having nominally pinned column bases with a value of $M_{\mathrm{OTM}}$ of $M_{\mathrm{SCl}}$

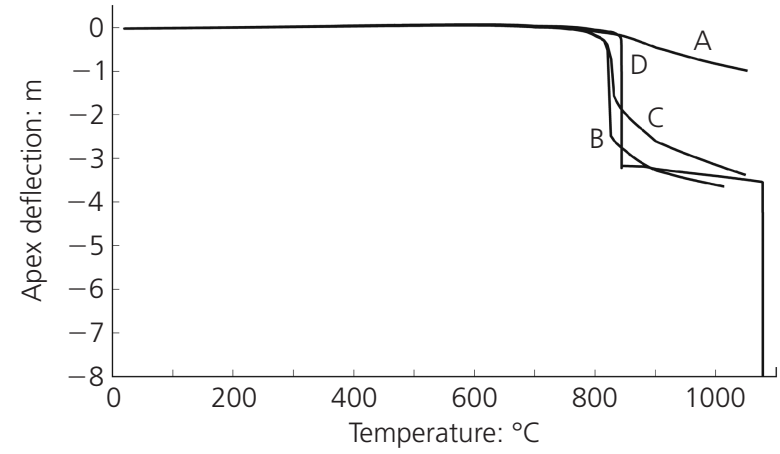

(a)

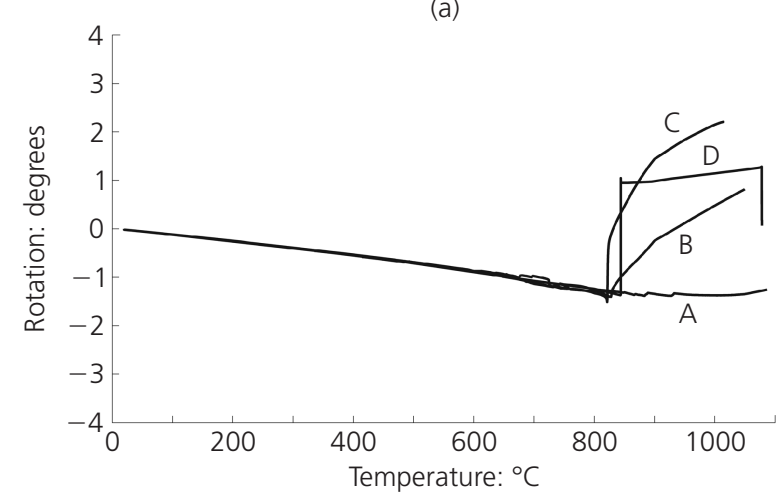

(b)

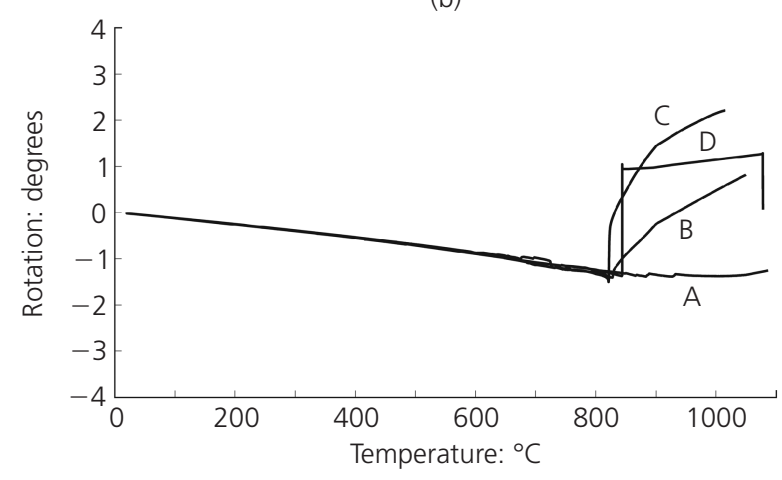

(c)

Figure 28. Variation of deflection and eaves rotation against temperature for standard building with nominally pinned partialstrength column base having a value of $M_{\text {OTM }}$ of $2 \mathrm{MsCl}$

(122.4 kN m) for different fire scenarios: (a) apex deflection:

(b) left eaves rotation; (c) right eaves rotation

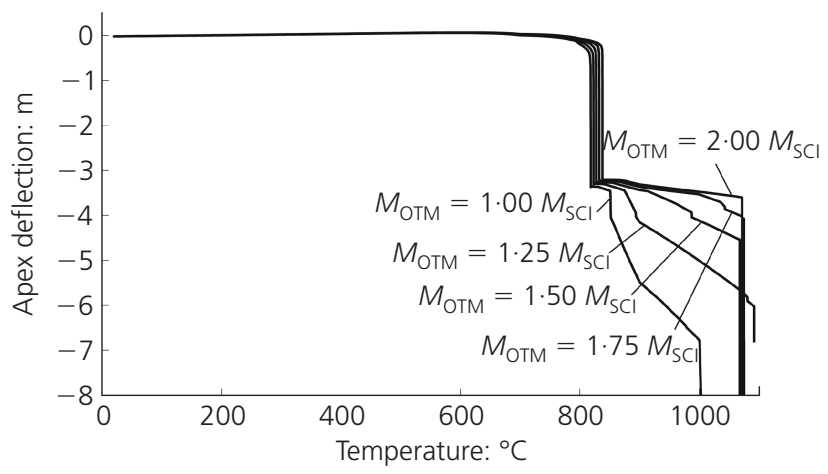

(a)

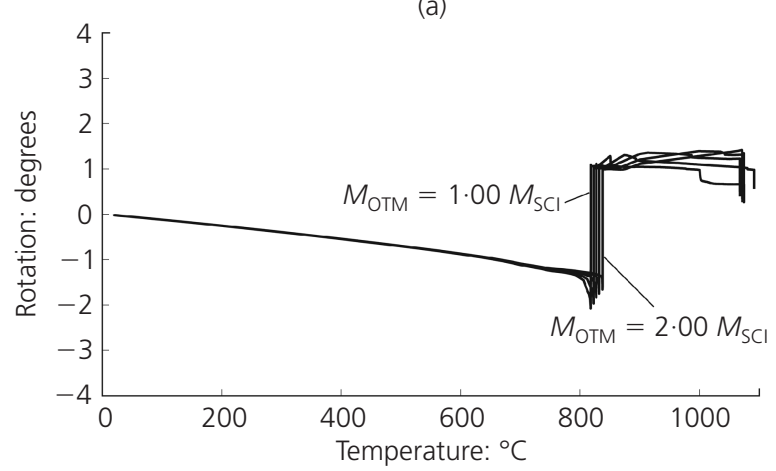

(b)

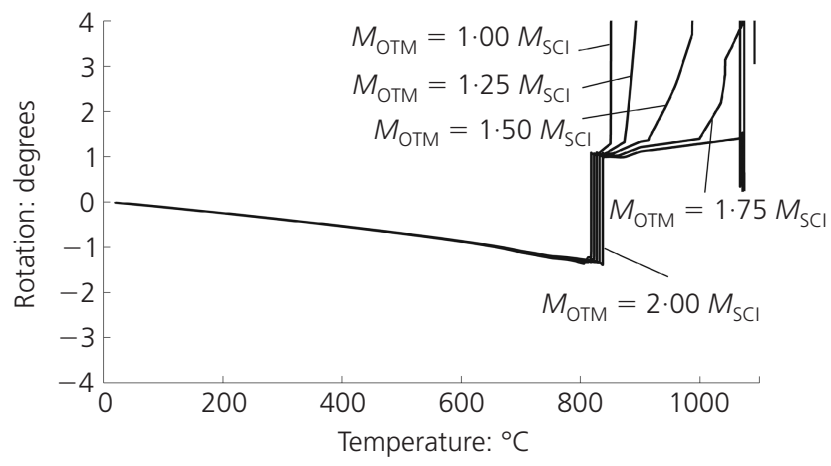

(c)

Figure 29. Variation of deflection and eaves rotation against temperature for standard building with nominally pinned partialstrength column base having different Mотм: (a) apex deflection: (b) left eaves rotation; (c) right eaves rotation 


\begin{tabular}{lccc}
\hline Fire scenario & $\begin{array}{c}\text { Snap-through- } \\
\text { buckling } \\
\text { temperature: }{ }^{\circ} \mathrm{C}\end{array}$ & $\begin{array}{c}\text { Maximum outward } \\
\text { column rotation by } \\
890^{\circ} \mathrm{C} \text { : degrees }\end{array}$ & $\begin{array}{c}\text { Maximum inward } \\
\text { column rotation by } \\
890^{\circ} \mathrm{C} \text { : degrees }\end{array}$ \\
\hline A & $>1100$ & 1.4 & $\mathrm{n} / \mathrm{a}$ \\
B & 831 & 1.4 & 1.5 \\
C & 826 & 1.5 & 1.5 \\
D & 822 & 1.4 & 3.25
\end{tabular}

Table 8. Summary of behaviour of standard building having nominally pinned column bases with a value of $M_{\text {OTM }}$ of $2 M_{\text {SCI }}$

UB $533 \times 210 \times 82$

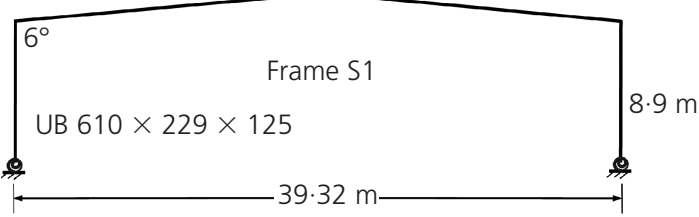

UB $406 \times 178 \times 54$

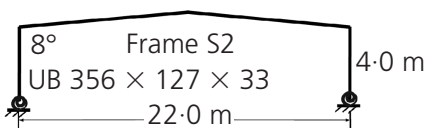

UB $457 \times 191 \times 74$

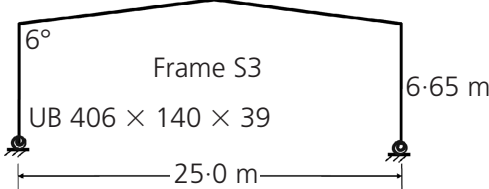

Figure 30. Frames designed from a survey of practising engineers (Lim et al., 2005)

\begin{tabular}{|c|c|c|c|c|c|c|c|c|c|c|c|}
\hline Frame & $L: m$ & $h: m$ & $\begin{array}{c}\theta: \\
\text { degrees }\end{array}$ & $L / h$ & Column section & Rafter section & $\begin{array}{l}M_{p, r a f:} \\
k N \text { m }\end{array}$ & $\begin{array}{l}M_{p, \text { col }}: \\
k N \text { m }\end{array}$ & $\begin{array}{l}\text { MsCl: } \\
\text { kN m }\end{array}$ & $\begin{array}{l}M_{\mathrm{scl}} / \\
M_{\mathrm{p}, \mathrm{col}}\end{array}$ & $r$ \\
\hline Standard & 22 & $5 \cdot 7$ & 6 & 3.9 & $457 \times 152 \times 52$ & $457 \times 152 \times 52$ & 296 & 296 & 61 & 0.21 & 0.09 \\
\hline $\mathrm{S} 1$ & $39 \cdot 3$ & 8.9 & 6 & $4 \cdot 4$ & $610 \times 229 \times 125$ & $533 \times 210 \times 82$ & 642 & 1341 & 258 & $0 \cdot 19$ & $0 \cdot 20$ \\
\hline $\mathrm{S} 2$ & $22 \cdot 0$ & $4 \cdot 0$ & 8 & $5 \cdot 5$ & $406 \times 178 \times 54$ & $356 \times 127 \times 33$ & 110 & 253 & 75 & $0 \cdot 30$ & 0.22 \\
\hline S3 & $25 \cdot 0$ & $6 \cdot 7$ & 6 & $3 \cdot 8$ & $457 \times 191 \times 74$ & $406 \times 140 \times 39$ & 168 & 453 & 115 & $0 \cdot 25$ & $0 \cdot 24$ \\
\hline P1 & $40 \cdot 0$ & $6 \cdot 0$ & 6 & $6 \cdot 7$ & $686 \times 254 \times 140$ & $533 \times 210 \times 92$ & 649 & 1253 & 196 & $0 \cdot 16$ & 0.18 \\
\hline P2 & $35 \cdot 0$ & $6 \cdot 0$ & 6 & $5 \cdot 8$ & $686 \times 254 \times 125$ & $533 \times 210 \times 82$ & 566 & 1098 & 148 & $0 \cdot 14$ & $0 \cdot 16$ \\
\hline P3 & $30 \cdot 0$ & $6 \cdot 0$ & 6 & $5 \cdot 0$ & $610 \times 229 \times 101$ & $457 \times 191 \times 67$ & 405 & 792 & 120 & $0 \cdot 15$ & $0 \cdot 12$ \\
\hline P4 & $25 \cdot 0$ & $6 \cdot 0$ & 6 & $4 \cdot 2$ & $533 \times 210 \times 82$ & $406 \times 178 \times 54$ & 290 & 566 & 90 & $0 \cdot 16$ & 0.16 \\
\hline P5 & $20 \cdot 0$ & $6 \cdot 0$ & 6 & $3 \cdot 3$ & $457 \times 191 \times 67$ & $406 \times 140 \times 39$ & 181 & 405 & 57 & 0.14 & 0.15 \\
\hline P6 & $15 \cdot 0$ & $6 \cdot 0$ & 6 & $2 \cdot 5$ & $356 \times 171 \times 45$ & $305 \times 102 \times 28$ & 111 & 213 & 43 & $0 \cdot 20$ & $0 \cdot 15$ \\
\hline P7 & $40 \cdot 0$ & $8 \cdot 0$ & 6 & $5 \cdot 0$ & $762 \times 267 \times 147$ & $533 \times 210 \times 92$ & 649 & 1418 & 213 & 0.15 & 0.18 \\
\hline P8 & $35 \cdot 0$ & $8 \cdot 0$ & 6 & $4 \cdot 4$ & $686 \times 254 \times 125$ & $533 \times 210 \times 82$ & 566 & 1098 & 174 & $0 \cdot 16$ & 0.16 \\
\hline P9 & $30 \cdot 0$ & $8 \cdot 0$ & 6 & $3 \cdot 8$ & $610 \times 229 \times 101$ & $457 \times 191 \times 67$ & 405 & 792 & 143 & $0 \cdot 18$ & 0.17 \\
\hline P10 & $25 \cdot 0$ & $8 \cdot 0$ & 6 & $3 \cdot 1$ & $533 \times 210 \times 82$ & $406 \times 178 \times 54$ & 290 & 566 & 108 & $0 \cdot 19$ & 0.16 \\
\hline P11 & $20 \cdot 0$ & $8 \cdot 0$ & 6 & $2 \cdot 5$ & $457 \times 191 \times 67$ & $406 \times 140 \times 39$ & 181 & 405 & 67 & $0 \cdot 17$ & 0.15 \\
\hline P12 & $15 \cdot 0$ & $8 \cdot 0$ & 6 & 1.9 & $356 \times 171 \times 45$ & $305 \times 102 \times 28$ & 111 & 213 & 59 & 0.28 & $0 \cdot 16$ \\
\hline P13 & $40 \cdot 0$ & $10 \cdot 0$ & 6 & $4 \cdot 0$ & $762 \times 267 \times 147$ & $610 \times 229 \times 101$ & 792 & 1418 & 243 & $0 \cdot 17$ & 0.15 \\
\hline P14 & $35 \cdot 0$ & $10 \cdot 0$ & 6 & $3 \cdot 5$ & $686 \times 254 \times 125$ & $533 \times 210 \times 82$ & 566 & 1098 & 200 & $0 \cdot 18$ & $0 \cdot 16$ \\
\hline P15 & $30 \cdot 0$ & $10 \cdot 0$ & 6 & $3 \cdot 0$ & $610 \times 229 \times 113$ & $457 \times 191 \times 67$ & 405 & 902 & 138 & $0 \cdot 15$ & $0 \cdot 17$ \\
\hline P16 & $25 \cdot 0$ & $10 \cdot 0$ & 6 & $2 \cdot 5$ & $533 \times 210 \times 92$ & $406 \times 178 \times 54$ & 290 & 649 & 100 & $0 \cdot 15$ & $0 \cdot 16$ \\
\hline P17 & $20 \cdot 0$ & $10 \cdot 0$ & 6 & $2 \cdot 0$ & $457 \times 191 \times 67$ & $406 \times 140 \times 39$ & 181 & 405 & 89 & $0 \cdot 22$ & $0 \cdot 16$ \\
\hline P18 & $15 \cdot 0$ & $10 \cdot 0$ & 6 & $1 \cdot 5$ & $356 \times 171 \times 51$ & $305 \times 102 \times 28$ & 111 & 246 & 48 & $0 \cdot 19$ & $0 \cdot 16$ \\
\hline P19 & $40 \cdot 0$ & $12 \cdot 0$ & & $3 \cdot 3$ & $762 \times 267 \times 147$ & $610 \times 229 \times 101$ & 792 & 1098 & 344 & $0 \cdot 31$ & $0 \cdot 15$ \\
\hline P20 & $35 \cdot 0$ & $12 \cdot 0$ & 6 & $2 \cdot 9$ & $686 \times 254 \times 125$ & $533 \times 210 \times 82$ & 566 & 1098 & 225 & $0 \cdot 21$ & $0 \cdot 16$ \\
\hline P21 & $30 \cdot 0$ & $12 \cdot 0$ & 6 & $2 \cdot 5$ & $610 \times 229 \times 113$ & $457 \times 191 \times 67$ & 405 & 902 & 154 & $0 \cdot 17$ & $0 \cdot 17$ \\
\hline P22 & $25 \cdot 0$ & $12 \cdot 0$ & 6 & $2 \cdot 1$ & $533 \times 210 \times 92$ & $406 \times 178 \times 54$ & 290 & 649 & 111 & $0 \cdot 17$ & $0 \cdot 17$ \\
\hline P23 & $20 \cdot 0$ & $12 \cdot 0$ & 6 & $1 \cdot 7$ & $457 \times 191 \times 67$ & $406 \times 140 \times 39$ & 181 & 405 & 100 & 0.25 & 0.16 \\
\hline
\end{tabular}

Table 9. Parameters of frames used in parametric study 


\subsection{Scope of parametric study}

In total, 27 portal frames are used for the parametric study. The dimensions of these frames are shown in Table 9. As can be seen from Table 9, the section sizes, moment capacities of the sections, as well as $M_{\mathrm{SCI}}$ are provided. Also included in Table 9 are the ratios of $M_{\mathrm{SCI}}$ to the plastic moment capacity of the column, $M_{\mathrm{c}, \mathrm{pl}}$, which range from $0 \cdot 14$ to $0 \cdot 3$.

Frames S1, S2 and S3 are shown in Figure 30. These frames are taken from designs reported in a survey of portal frames by practising engineers (Lim et al., 2005). Frames P1 to P23 are designed by the present authors based on charts presented in Todd (1996).

For all the frames investigated in the parametric study, the column bases are nominally pinned. A uniformly distributed load of $0.2 \mathrm{kN} / \mathrm{m}^{2}$ is applied on the roof; a nominal horizontal force of $0.5 \%$ of the vertical load is applied at the eaves. Values of $M_{\mathrm{OTM}}$ of both $M_{\mathrm{SCI}}$ and $2 M_{\mathrm{SCI}}$ are considered.

\subsection{Results of parametric study}

Table 10 shows the parametric study results for column rotation for three values of $M_{\mathrm{OTM}}: M_{\mathrm{SCI}}, 1 \cdot 5 M_{\mathrm{SCI}}$ and $2 M_{\mathrm{SCI}}$. As expected, increasing $M_{\mathrm{OTM}}$ from $M_{\mathrm{SCI}}$ to $2 M_{\mathrm{SCI}}$ has very little effect on the outward rotation. For the column base having a value of $M_{\mathrm{OTM}}$ of $M_{\mathrm{SCI}}$, the average maximum outward rotation is $1.8^{\circ}$, which is of a similar order of magnitude to the $1^{\circ}$ specified by the SCI design method. Table 10 also shows the inward rotations. As expected, the rotations are much higher than the $1^{\circ}$ specified by the SCI design method.

Similarly, in terms of snap-through-buckling temperatures, there is very little difference in increasing $M_{\mathrm{OTM}}$ from $M_{\mathrm{SCI}}$ to $2 M_{\mathrm{SCI}}$. Both the snap-through-buckling temperatures and collapse temperatures are shown in Table 11. As can be seen, the increase in the snap-through-buckling temperature, as a result of increasing $M_{\mathrm{OTM}}$ from $M_{\mathrm{SCI}}$ to $2 M_{\mathrm{SCI}}$ is only $10^{\circ} \mathrm{C}$.

However, in terms of collapse temperatures, the majority of

\begin{tabular}{|c|c|c|c|c|c|c|}
\hline \multirow[t]{2}{*}{ Frame } & \multicolumn{3}{|c|}{ Maximum outward column rotation by $890^{\circ} \mathrm{C}$ : degrees } & \multicolumn{3}{|c|}{ Maximum inward column rotation by $890^{\circ} \mathrm{C}$ : degrees } \\
\hline & $M_{\mathrm{OTM}}=M_{\mathrm{SCl}}$ & $M_{\mathrm{OTM}}=1.5 \mathrm{MSCl}_{\mathrm{SC}}$ & $M_{\mathrm{OTM}}=2 M_{\mathrm{SCl}}$ & $M_{\mathrm{OTM}}=M_{\mathrm{SCl}}$ & $M_{\mathrm{OTM}}=1.5 \mathrm{MSCl}_{\mathrm{SC}}$ & $M_{\mathrm{OTM}}=2 \mathrm{MSCl}_{\mathrm{S}}$ \\
\hline Standard & 1.7 & 1.5 & 1.5 & Collapsed & 8.4 & 1.5 \\
\hline S1 & $3 \cdot 7$ & 1.6 & 1.6 & Collapsed & Collapsed & $22 \cdot 0$ \\
\hline S2 & $3 \cdot 8$ & $3 \cdot 8$ & 3.6 & Collapsed & Collapsed & $3 \cdot 0$ \\
\hline S3 & $1 \cdot 3$ & 1.4 & $1 \cdot 4$ & Collapsed & Collapsed & 4.9 \\
\hline P1 & $2 \cdot 6$ & $2 \cdot 6$ & $2 \cdot 6$ & Collapsed & Collapsed & 1.0 \\
\hline P2 & $2 \cdot 9$ & $2 \cdot 4$ & $2 \cdot 3$ & Collapsed & Collapsed & $2 \cdot 6$ \\
\hline P3 & 3.6 & 3.0 & $2 \cdot 4$ & Collapsed & $11 \cdot 5$ & $2 \cdot 8$ \\
\hline P4 & $2 \cdot 7$ & 1.9 & 1.4 & Collapsed & $13 \cdot 7$ & $3 \cdot 5$ \\
\hline P5 & $2 \cdot 0$ & 1.9 & 1.8 & Collapsed & $25 \cdot 5$ & $8 \cdot 1$ \\
\hline P6 & $1 \cdot 1$ & $1 \cdot 1$ & $1 \cdot 1$ & Collapsed & $14 \cdot 2$ & $3 \cdot 6$ \\
\hline P7 & $2 \cdot 2$ & $2 \cdot 1$ & $2 \cdot 0$ & Collapsed & Collapsed & $3 \cdot 3$ \\
\hline P8 & $2 \cdot 9$ & $2 \cdot 3$ & $2 \cdot 0$ & Collapsed & $13 \cdot 9$ & $3 \cdot 3$ \\
\hline P9 & $2 \cdot 1$ & 1.9 & 1.8 & Collapsed & 11.8 & 2.9 \\
\hline P10 & $1 \cdot 3$ & $1 \cdot 3$ & $1 \cdot 3$ & Collapsed & $12 \cdot 3$ & $3 \cdot 4$ \\
\hline P11 & $1 \cdot 1$ & $1 \cdot 1$ & $1 \cdot 1$ & Collapsed & $23 \cdot 1$ & $6 \cdot 4$ \\
\hline P12 & 0.8 & 0.8 & 0.8 & $52 \cdot 1$ & $4 \cdot 3$ & $2 \cdot 8$ \\
\hline P13 & $2 \cdot 4$ & $2 \cdot 0$ & 1.9 & Collapsed & $12 \cdot 6$ & 3.0 \\
\hline P14 & $1 \cdot 7$ & 1.6 & 1.4 & Collapsed & $12 \cdot 7$ & $3 \cdot 2$ \\
\hline P15 & $1 \cdot 3$ & $1 \cdot 3$ & $1 \cdot 3$ & Collapsed & $26 \cdot 9$ & $7 \cdot 2$ \\
\hline P16 & $1 \cdot 1$ & $1 \cdot 1$ & $1 \cdot 1$ & Collapsed & $36 \cdot 2$ & 8.9 \\
\hline P17 & 0.8 & 0.8 & 0.8 & Collapsed & $9 \cdot 1$ & $2 \cdot 6$ \\
\hline P18 & 0.7 & 0.7 & 0.7 & $67 \cdot 3$ & 8.5 & $6 \cdot 0$ \\
\hline P19 & 1.4 & $1 \cdot 3$ & $1 \cdot 3$ & $31 \cdot 5$ & $3 \cdot 4$ & $1 \cdot 7$ \\
\hline P20 & $1 \cdot 3$ & $1 \cdot 2$ & $1 \cdot 2$ & Collapsed & $11 \cdot 3$ & $2 \cdot 8$ \\
\hline P21 & 1.0 & 1.0 & 1.0 & Collapsed & $25 \cdot 8$ & 6.6 \\
\hline P22 & 0.9 & 0.9 & 0.9 & Collapsed & $12 \cdot 7$ & 8.0 \\
\hline P23 & 0.7 & 0.7 & 0.7 & $57 \cdot 0$ & $7 \cdot 4$ & $3 \cdot 2$ \\
\hline Average & 1.8 & 1.6 & 1.5 & & & \\
\hline
\end{tabular}

Table 10. Parametric study results for column rotation 
frames having a value of $M_{\mathrm{OTM}}$ of $M_{\mathrm{SCI}}$ have collapsed by $890^{\circ} \mathrm{C}$. The effect of increasing $M_{\mathrm{OTM}}$ from $M_{\mathrm{SCI}}$ to $2 M_{\mathrm{SCI}}$ results in the average collapse temperature being increased from $845^{\circ} \mathrm{C}$ to $1034^{\circ} \mathrm{C}$. The results for $M_{\mathrm{OTM}}$ having a value of $1.5 M_{\mathrm{SCI}}$ are also shown in Table 11. As can be seen, the average collapse temperature for a value of $M_{\mathrm{OTM}}$ of $1.5 M_{\mathrm{SCI}}$ is $958^{\circ} \mathrm{C}$, which is higher than the temperature assumed in the SCI design of $890^{\circ} \mathrm{C}$.

\subsection{Comparison against Wong's method}

As discussed in section 6.1, Wong (2001) described a method for determining the snap-through-buckling temperature for pinned column base portal frames. Table 12 shows a comparison of the snap-through-buckling temperature of Wong's method and the Abaqus model using nominally pinned column bases and $M_{\mathrm{OTM}}$ of $M_{\mathrm{SCI}}$. It can be seen that Wong's method is slightly underconservative, even though it is based on pinned column bases. Wong's method is, however, useful for quickly assessing the snapthrough-buckling temperature.

\section{Conclusion}

The following conclusions can be drawn.

(a) The 3D model increases the collapse temperature and reduces the rotations, but the number of frames in fire is significant.

(b) The SCI method does not take into account the partial strength of the column base. If the partial strength of the column base is taken into account, the column base rotational stiffness has little effect on the collapse behaviour of the frame, with the column base behaving as a pin once the column base moment capacity has been exceeded.

(c) The 2D frames considered in the parametric study all collapsed before $890^{\circ} \mathrm{C}$ when the rotational strength of the column base was $M_{\mathrm{SCI}}$. However, when the rotational strength of the column base was increased to $2 M_{\mathrm{SCI}}$ all the frames were stable at $890^{\circ} \mathrm{C}$. Intermediate results for $1.5 M_{\mathrm{SCI}}$ were also provided. It is acknowledged by the current authors that

\begin{tabular}{|c|c|c|c|c|c|c|}
\hline \multirow{2}{*}{ Frame } & \multicolumn{3}{|c|}{ Snap-through-buckling temperature: ${ }^{\circ} \mathrm{C}$} & \multicolumn{3}{|c|}{ Collapse temperature: ${ }^{\circ} \mathrm{C}$} \\
\hline & $M_{\mathrm{OTM}}=M_{\mathrm{SCl}}$ & $M_{\mathrm{OTM}}=1 \cdot 5 \mathrm{MSCl}$ & $M_{\mathrm{OTM}}=2 \mathrm{MSCl}_{\mathrm{S}}$ & $M_{\mathrm{OTM}}=M_{\mathrm{SCl}}$ & $M_{\mathrm{OTM}}=1 \cdot 5 \mathrm{MSCl}$ & $M_{\mathrm{OTM}}=2 \mathrm{MSCl}_{\mathrm{S}}$ \\
\hline Standard & 818 & 828 & 838 & 869 & 986 & 1071 \\
\hline S1 & 620 & 621 & 624 & 664 & 695 & 979 \\
\hline $\mathrm{S} 2$ & 672 & 682 & 694 & 762 & 783 & 936 \\
\hline S3 & 643 & 645 & 647 & 698 & 875 & 918 \\
\hline P1 & 711 & 721 & 736 & 793 & 850 & 1047 \\
\hline $\mathrm{P} 2$ & 737 & 741 & 751 & 808 & 880 & 1057 \\
\hline P3 & 781 & 786 & 793 & 885 & 1042 & 1054 \\
\hline P4 & 732 & 736 & 742 & 849 & 941 & 1008 \\
\hline P5 & 742 & 743 & 747 & 793 & 974 & 1031 \\
\hline P6 & 740 & 740 & 741 & 808 & 941 & 977 \\
\hline P7 & 701 & 702 & 710 & 792 & 881 & 1063 \\
\hline P8 & 731 & 735 & 741 & 847 & 1001 & 1053 \\
\hline P9 & 725 & 728 & 733 & 859 & 967 & 1043 \\
\hline P10 & 731 & 732 & 734 & 852 & 974 & 1048 \\
\hline P11 & 745 & 746 & 747 & 791 & 940 & 1027 \\
\hline P12 & 746 & 746 & 747 & 985 & 985 & 986 \\
\hline P13 & 743 & 746 & 751 & 863 & 987 & 1068 \\
\hline P14 & 729 & 732 & 736 & 859 & 983 & 1061 \\
\hline P15 & 723 & 724 & 726 & 795 & 967 & 1053 \\
\hline P16 & 730 & 728 & 731 & 776 & 1032 & 1060 \\
\hline P17 & 750 & 750 & 751 & 892 & 1002 & 1010 \\
\hline P18 & 748 & 749 & 749 & 1026 & 1040 & 1048 \\
\hline P19 & 740 & 741 & 743 & 1096 & 1097 & 1098 \\
\hline P20 & 728 & 728 & 729 & 882 & 979 & 1054 \\
\hline P21 & 724 & 725 & 726 & 790 & 994 & 1058 \\
\hline P22 & 727 & 729 & 729 & 782 & 1041 & 1063 \\
\hline P23 & 751 & 752 & 753 & 1007 & 1029 & 1045 \\
\hline Average & 725 & 731 & 735 & 845 & 954 & 1034 \\
\hline
\end{tabular}




\begin{tabular}{|c|c|c|}
\hline \multirow[t]{2}{*}{ Frame } & \multicolumn{2}{|c|}{ Snap-through buckling temperature } \\
\hline & Abaqus: ${ }^{\circ} \mathrm{C}$ & Wong's method: ${ }^{\circ} \mathrm{C}$ \\
\hline Standard & 809 & 709 \\
\hline S1 & 618 & 757 \\
\hline $\mathrm{S} 2$ & 653 & 661 \\
\hline S3 & 636 & 679 \\
\hline P1 & 702 & 761 \\
\hline P2 & 728 & 774 \\
\hline P3 & 773 & 769 \\
\hline P4 & 724 & 770 \\
\hline P5 & 730 & 765 \\
\hline P6 & 725 & 773 \\
\hline P7 & 701 & 755 \\
\hline P8 & 725 & 770 \\
\hline P9 & 718 & 765 \\
\hline P10 & 720 & 767 \\
\hline P11 & 729 & 762 \\
\hline P12 & 720 & 771 \\
\hline P13 & 737 & 777 \\
\hline P14 & 723 & 768 \\
\hline P15 & 716 & 763 \\
\hline P16 & 718 & 765 \\
\hline P17 & 726 & 761 \\
\hline P18 & 712 & 770 \\
\hline P19 & 738 & 776 \\
\hline P20 & 725 & 766 \\
\hline P21 & 714 & 761 \\
\hline P22 & 715 & 764 \\
\hline P23 & 722 & 760 \\
\hline
\end{tabular}

Table 12. Comparison of snap-through buckling temperature against Wong's method

this conclusion should not be taken too generally, as only a limited number of frames were considered.

(d) The average outward rotation of the columns where the rotational strength of the column base was $M_{\mathrm{SCI}}$ was $1 \cdot 8^{\circ}$. This outward rotation was only slightly higher than the $1^{\circ}$ assumed by the SCI design method.

(e) The inward rotation was significantly higher than $1^{\circ}$.

( $f$ ) It has been shown that the value of the overturning moment, calculated in accordance with the SCI design method, may not be sufficient to prevent collapse of the frame before $890^{\circ} \mathrm{C}$. However, by taking into account both the number of bays in fire, and the strength of the column base, a frame may be able to be shown to satisfy the assumptions of the SCI design criteria of the columns remaining $1^{\circ}$ from the vertical and stability up to a temperature of $890^{\circ} \mathrm{C}$.

( $g$ ) The safety implication of the SCI design guidance not being sufficient has not been explored in this paper, other than to note that frames designed on the basis of the SCI design guidance may collapse at a lower temperature than expected.

\section{REFERENCES}

Ali HM, Senseny ES and Alpert RL (2004) Lateral displacement and collapse of single-storey steel frames in uncontrolled fires. Engineering Structures 26(5): 593-607.

Bong MW (2005) Structural Fire Performance Of Steel Portal Frame Buildings. MSc thesis, University of Canterbury, New Zealand.

BSI (2005) BS EN 1993-1-2: Eurocode 3: Design of steel structures. Part 1-2: General rules- Structural fire design. BSI, London, UK.

DEW (Department of Environment and the Welsh Office) (1991) The Building Regulations: Fire Safety, Approved Document B. Her Majesty's Stationery Office, London, UK.

Franssen JM, Kodur VK and Mason M (2002) User's Manual for SAFIR 2001: A Computer Program for Analysis of Structures Submitted to Fire. University of Liege, Liege, Belgium.

Franssen JM and Gens F (2004) Dynamic analysis used to cope with partial and temporary failure. In Proceedings of the Third International Workshop - Structures in Fire, 10-11 May 2004 (Franssen et al. (ed.)). National Research Council of Canada, Ottawa, ON, Canada, pp. 297-310.

Huang Z, Burgess IW and Plank RJ (2004) 3D modelling of beam-columns with general cross-sections in fire. In Proceedings of the Third International Workshop - Structures in Fire, 10-11 May 2004 (Franssen et al. (ed.)). National Research Council of Canada, Ottawa, ON, Canada, pp. 323334.

ISO (International Organisation for Standardisation) (1975) Fire Resistance Tests - Elements of Building Construction. ISO, Geneva, Switzerland.

Kaitila O (2002) Finite Element Modeling Of Cold-Formed Steel Members At High Temperatures. Thesis (licentiate), Helsinki University, Finland.

Lim JBP, King CM, Rathbone AJ, Davies JM and Edmonson V (2005) Eurocode 3 and the in-plane stability of portal frames. The Structural Engineer 83(21): 43-49.

Moss PJ, Dhakal RP, Bong MW and Buchanan AH (2009) Design of steel portal frames for fire safety. Journal of Constructional Steel Research 65(5): 1216-1224.

O'Meagher AJ, Bennetts ID, Daywansa PH, Thomas IR and BHP Research (1992) Design of single storey industrial buildings for fire resistances. Journal of the Australian Institute of Steel Construction 26(2): 1-17.

Salter PR, Malik AS and King CM (2004) Design of Single-Span Steel Portal Frames to BS 5950-1:2000. The Steel Construction Institute, Ascot, UK, publication no. P252.

Simms W and Newman G (2002) Single-storey steel framed buildings in fire boundary conditions. The Steel Construction Institute, Ascot, UK, Publication No. P313.

Simulia (2009) Abaqus Analysis User's Manual (Version 6.9-3). Dassault Systemés, Vélizy-Villacoublay, France.

SNZ (Standards New Zealand) (1992) NZS 4203: Code of practice 
for general structural design, and design loadings for buildings (known as Loadings Code). SNZ, Wellington, New Zealand.

SNZ (1997) NZS 3404: Steel structures standard. SNZ, Wellington, New Zealand.

Song YY, Huang Z, Burgess IW and Plank RJ (2008) A new design method for industrial portal frames in fire.

Proceedings of the 5th International Conference on Structure in Fire (SiF-08), 28-30 May 2008. Nanyang Technological University, Singapore, pp. 302-312.

Song YY, Huang Z, Burgess IW and Plank RJ (2009) The behaviour of single-storey industrial steel frames in fire. International Journal of Advanced Steel Construction 5(3): 289-302.

Song YY (2009) Analysis of Steel Portal Frames Under Fire Conditions. PhD thesis, University of Sheffield, Sheffield, UK
Steadmans A (2010) Purlins, Rails and Eaves Beams - Load Tables. A Steadmans and Sons, Carlisle, UK.

Todd AJ (1996) Portal Frames. Structural Advisory Service, British Steel, London, UK.

Vassart O, Brasseur M, Cajot LG, Obiala R, Griffin A, Spasov Y, Renaud C, Zhao B, Arce C and Quintana J (2007) Fire Safety of Industrial Halls and Low-Rise Buildings: Final Report. Technical Steel Research, European Commission, Brussels, Belgium.

Wong Y (2001) The Structural Response of Industrial Portal Frame Structures in Fire. PhD thesis, University of Sheffield, Sheffield, UK.

Zha XX (2003) FE analysis of fire resistance of concrete filled CHS columns. Journal of Constructional Steel Research 59(6): 769-779.

\section{WHAT DO YOU THINK?}

To discuss this paper, please email up to 500 words to the editor at journals@ice.org.uk. Your contribution will be forwarded to the author(s) for a reply and, if considered appropriate by the editorial panel, will be published as a discussion in a future issue of the journal.

Proceedings journals rely entirely on contributions sent in by civil engineering professionals, academics and students. Papers should be 2000-5000 words long (briefing papers should be 1000-2000 words long), with adequate illustrations and references. You can submit your paper online via www.icevirtuallibrary.com/content/journals, where you will also find detailed author guidelines. 